\title{
Impact of Demand Response on Reliability Enhancement in Distribution Networks
}

\author{
Mohammad Reza Mansouri, Mohsen Simab * and Bahman Bahmani Firouzi
}

Citation: Mansouri, M.R.; Simab, M.; Bahmani Firouzi, B. Impact of Demand Response on Reliability Enhancement in Distribution Networks. Sustainability 2021, 13, 13201. https://doi.org/10.3390/ su132313201

Academic Editors: Sara Ahmed and Ning Kang

Received: 4 September 2021

Accepted: 22 November 2021

Published: 29 November 2021

Publisher's Note: MDPI stays neutral with regard to jurisdictional claims in published maps and institutional affiliations.

Copyright: (c) 2021 by the authors. Licensee MDPI, Basel, Switzerland. This article is an open access article distributed under the terms and conditions of the Creative Commons Attribution (CC BY) license (https:// creativecommons.org/licenses/by/ $4.0 /)$.
Department of Electrical Engineering, Marvdasht Branch, Islamic Azad University, Marvdasht 73711-13119, Iran; mansouri@iaulamerd.ac.ir (M.R.M.); Bahman_bahmani@miau.ac.ir (B.B.F.)

* Correspondence: msimab@miau.ac.ir

Abstract: This paper presents an innovative instantaneous pricing scheme for optimal operation and improved reliability for distribution systems (DS). The purpose of the proposed program is to maximize the operator's expected profit under various risk-taking conditions, such that the customers pay the minimum cost to supply energy. Using the previous information of the energy consumption for each customer, a customer baseline load (CBL) is defined; the energy price for consumption costs higher and lower than this level would be different. The proposed scheme calculates the difference between the baseline load and the consumption curve with the electricity market price instead of calculating the total consumption of the customers with the unstable price of the electricity market, which is uncertain. In the proposed tariff, the developed cost and load models are included in the distribution system operation problem, and the objective function is modeled as a mixed integer linear programming (MILP) problem. Also, the effect of demand response (DR) and elasticity on the load curve, the final profit of the distribution system operator, and payment risk and operation costs are examined. Since there are various uncertainties in the smart distribution grid, the calculations being time-consuming and volumetric is important in the evaluation of reliability indices. Thus, when computation volume can be decreased and computation speed can be increased, analytical reliability analysis methods can be used, as they were in the present work. Finally, the changes in the reliability indices were calculated for the ratio of the customers' sensitivity to the price and the customers' participation in the proposed tariff using an analytical method based on Monte Carlo simulation (MCS). The results showed the efficiency of the proposed method in increasing the operator profit, reducing the operation costs, and enhancing the reliability indices.

Keywords: demand response (DR); distribution system (DS); real-time pricing (RTP); reliability indices

\section{Introduction}

\subsection{Aim}

Demand response, as the main part of future smart grids, plays a significant role in instantaneous pricing tariffs in the electricity industry. The instantaneous pricing tariff is known as the most direct and efficient price-based demand response approach. Schedulers are trying to employ price-based demand response instead of direct interruptible loads [1,2]. There is a direct relationship between customers' power consumption and the electricity price. Thus, in this type of load, selecting a demand response program is of great importance [3]. An instantaneous pricing tariff program should be designed such that the operation costs are reduced and the distribution network reliability is increased. On the other hand, the program should provide sufficient incentive to attract customers. Various studies have been presented on energy pricing and reducing the distribution costs among customers [4]. The model proposed in this paper calculates the transmission, distribution, and energy costs independently and announces them in separate invoices. The best pricebased demand response program in distribution networks that can increase the operators' profit and cover the consumers' social welfare is real-time pricing [5]. On the one hand, 
the development of distribution networks with high energy demand, particularly in big cities, increases electricity consumption significantly, highlighting the role of distribution networks in supplying electricity. On the other hand, supplying reliable energy of high quality has attracted attention recently. Accordingly, evaluating the reliability and risk management of these networks is essential and important. In general, an analytical method and a method based on probabilistic simulations have been presented to evaluate reliability and risk management in smart distribution networks. Each method has some advantages and disadvantages. The advantage of probabilistic simulation methods is that various uncertainties of the distribution system and new conditions can be added, but the disadvantage is that it is time-consuming because of the numerous iterations of the calculations. Although mathematical modeling is used in analytical methods by simplification, and the computation time therefore decreases, the accuracy of the results also decreases, being far from reality. Here, a new framework is presented for calculating the load curve considering the participation level of the consumers in DR programs and self-elasticity. This load curve is based on base load and compares the consumption with the base load at each time instant to calculate the difference of the demand with the base load. Then, this demand curve is used to obtain the consumption-based reliability indices for distribution systems. Thus, this research followed three main objectives: first, developing a tariff for calculating the customers' invoice; second, calculating the profit and costs of the DSO; and third, calculating the reliability indices using a new framework based on load restoration.

\subsection{Literature Review}

In recent years, the performance of distribution networks has attracted attention in electricity markets. Also, the use of DR programs to improve the reliability of smart distribution networks is increasing. The authors of [6] presented an incentive-based DR program for optimal wind energy utilization in the market framework. The authors of [7] implemented a real-time pricing (RTP) tariff, resulting in optimal utilization of wind generators. This study assumed that the energy price in the market was equal to the marginal cost of hourly energy generation. In the other words, the impact of the application of market power by energy generation companies in the market at the consumption peak was ignored. Considering the operation constraints, this study aimed to maximize the total profit. In [8], a framework was proposed for determining optimal RTP price signals. While the electric energy industry is moving towards changing the power system structure, various problems and challenges, including transmission network congestion [9], electricity price spikes $[10,11]$, operation, and management, have emerged. In the emerging competitive electricity markets, congestion management plays an essential role in economical, safe, and stable operation of the power system [12]. With the development of demand-side management, it was decided to activate load and customers so that electricity market problems would be resolved with minimum cost. In line with this approach, various DR technologies and approaches have been developed [13] such that customers are more active in the electricity market and play their effective role as the fastest, cheapest, and most reliable tool for solving the electricity market's problems [14]. Since one of the most important operation costs is the cost of interruptions (penalty of unsupplied energy to customers), interruptions should be managed and reduced [15]. In [16], a mixed integer linear programming model (MILP) was used to solve the complicated problems of power systems. In [17], a novel bilevel method was used to schedule the smart distribution networks in the presence of demand response aggregators (DRA) and microgrids (MG). In this method, the upper level minimized the operational costs of the distribution system (DS) operator (DSO), while the lower level maximized the MG and DRA profits. In [18], a mixed integer nonlinear programming model (MINLP) was proposed for scheduling the development of multicarrier systems, including electricity and gas distribution networks. An optimal schedule was applied to minimize the investment costs and losses. Finally, an approach based on the Benders decomposition algorithm was presented to reduce the solution time. In ref. [19], a new framework was proposed for developing trade strategies for a distribution company 
(DisCO) with distributed generation (DG) units and electricity storage systems (ESSs) in the energy and retail markets. In this framework, thanks to its DG units and ESSs, such a DisCO acts as a price maker in the wholesale electricity market. The uncertainty associated with the demands across the distribution network was considered by a set of scenarios, with the demand elasticity further taken into account in the demand response program (DRP). Striving for optimal demand control and profit growth, a real-time pricing (RTP) scheme was considered as the best choice for the DisCOs. This was modeled by a bilevel optimization problem, the upper level of which included the maximum profit from selling energy to consumers under RTP programs and management of DG units, and the lower level of which included the wholesale market clearing and considered the constraints of the DC network to maximize social welfare. Even though the DisCO's profit grew in [19], consumers could not benefit from the DRP due to elasticity reduction. Thus, retail prices were not adjusted at peak consumption, and consumer payments increased. In [20], a bilevel DR program was presented for residential load adders in which the scheduling domain was a diverse set of loads based on the clustering model for the day-ahead market and real-time market. In [21], a probabilistic model was presented for simultaneous planning of energy and MG reserve with price-based DR participation. According to the findings of this study, the loads enhanced the system performance against uncertainties through participation in the energy storage schedule. In this model, the operation risk of countering the uncertainties that play an effective role in allocating reserve from resources was not considered. In [22], the effect of DR programs on energy scheduling and storage of an MG in the day-ahead market was studied. In this reference, the uncertainty of loads, renewable resources, and energy price in a scenario-based model were considered, but the effect of risk on energy storage resource scheduling was not evaluated. Refs. $[23,24]$ focused mainly on the security and reliability of MGs, countering with the operation uncertainties resulting from predicting the demand and supply. However, in the mentioned references, the effect of DR programs on capacity of the required storage under various risk-taking conditions of the operator was not studied.

In $[25,26]$, flexible loads were used to calculate the energy consumption of household appliances in different seasons of the year, but demand responsiveness and irresponsiveness were not compared. In [27], a model was presented for standard energy consumption based on the baseline load of the customers to increase the energy efficiency and reduce the energy consumption of the customers using DR programs. In $[28,29]$, novel demand-side management models were presented to enhance the efficiency of the smart grid based on scheduling smart household appliances with renewable energy resources and energy storage systems. Statistical studies showed that the electric energy distribution grids played a significant role in outages for customers [30,31]. On the other hand, reliable energy supply has also attracted attention in recent years. Accordingly, evaluating the reliability and risk management of these grids is very important $[32,33]$. Analytic methods and methods based on probabilistic simulations have been presented to evaluate reliability and risk management in smart grids [34-37]. Methods based on probabilistic simulations such as the Monte Carlo (MC) method cover various system uncertainties, and new conditions with new stochastic nature can be easily added [38-40]. However, it should be noted that these methods are time consuming, with heavy computations. When a large number of studies are required, this method is not responsive or efficient. In such conditions, the importance of using analytical methods grows [34,41,42].

One of these analytical methods is the Markov model. In [43-46], system reliability considering failure rate was calculated using the Markov model. In analytical methods, mathematical modeling is simplified, reducing the accuracy of the results and growing far from reality. On the contrary, in simulation methods, the real system is studied, and more accurate results are obtained. One simulation method that is widely used in analyzing the reliability of the electric systems is the MC method [47-49]. Monte Carlo simulation (MCS) is suitable for complicated systems, such as photovoltaic-wind systems, because its computational efficiency is independent of size and complexity. Studies conducted 
in the context of reliability evaluations have had some defects; for example, reliability evaluation and accurate failure rate calculation for all components have not been carried out, and a proper algorithm has not been used to execute the Monte Carlo method. In distribution networks, load restoration should be carried out to calculate reliability during fault occurrence so that the lost load is calculated. In [50], an analytical optimization model was presented for the restoration problem, and a novel formulation was used to reduce the number of binary variables. In [51], the restoration concept was defined by developing an MG, and a nonlinear problem was converted to a linear problem through approximation. In [52], the effect of renewable resources and their uncertainty on distribution system restoration was studied. Also, severe operational occurrences and the effects of demand response programs on distribution system performance in the restoration period were studied for restoring a distribution system. In [53], an approach based on Markov decision making was proposed for calculating restoration policy. In [54], a graph theory based on a particle swarm optimization (PSO) algorithm was presented for distribution system restoration. In this paper, the effects of restoration scheme and load harvest on distribution system reliability were studied. In [16], a distribution service restoration framework was modeled that could determine the optimal switching sequence and estimate the restoration time in the presence of remote-controllable switches, manual switches, and distributable DGs. This model was designed as a mixed integer linear programming model. The investigated studies had some shortcomings that might affect the decisions of a DSO. In this regard, in [3,9-13], although DR programs were used, the reliability of the distribution system was not investigated. In some articles (for example, [12-18]), the authors presented a framework for developing sell/purchase strategies for a distribution company in the energy and retail markets considering demand uncertainty, but none of them examined the effect of elasticity on consumption demand. In some studies, no pricing scheme was used, such that the customers of the distribution network were ignored (for example, [32-47]). In some articles, load restoration resources in the distribution system and network reliability were considered, but no plan was considered for pricing and participation levels of consumers (for instance, [32-49]). Also, in some models, the distribution network and optimal power flow were ignored (for example, $[46,48,49,54]$ ). Table 1 demonstrates the characteristics of previous studies along with the characteristics of the current study.

Table 1. Relevant features of previous studies.

\begin{tabular}{|c|c|c|c|c|c|c|c|}
\hline Reference & $\begin{array}{c}\text { Demand } \\
\text { Response } \\
\text { Program }\end{array}$ & Elasticity & $\begin{array}{l}\text { Reliability } \\
\text { Issue }\end{array}$ & $\begin{array}{l}\text { Power } \\
\text { Flow }\end{array}$ & Pricing Method & Approach & $\begin{array}{l}\text { Bill Paid by } \\
\text { Customers }\end{array}$ \\
\hline [4] & Yes & No & No & ACOPF & RTP & NLP & No \\
\hline [5] & Yes & No & Yes & ACOPF & RTP & MILP & Yes \\
\hline [6] & Yes & No & No & DCOPF & TOU & MILP & Yes \\
\hline [7] & Yes & Yes & No & No & RTP & NLP & No \\
\hline [8] & No & No & No & No & Dynamic pricing & LMI & No \\
\hline [9] & Yes & No & No & ACOPF & RTP & Genetic algorithm & No \\
\hline [10] & Yes & No & No & ACOPF & TOU & Fuzzy satisfying & No \\
\hline [11] & Yes & No & No & ACOPF & RTP & MILP & No \\
\hline [12] & Yes & No & No & NO & RTP & LP & Yes \\
\hline [13] & Yes & No & No & ACOPF & No & MILP & No \\
\hline [14] & Yes & No & No & ACOPF & $\mathrm{LC}$ & MILP & No \\
\hline [15] & Yes & Yes & No & ACOPF & RTP & NLP & No \\
\hline [16] & No & No & No & ACOPF & No & MILP & No \\
\hline [17] & Yes & No & No & ACOPF & RTP & Big-M method & Yes \\
\hline [18] & Yes & No & No & ACOPF & Various methods & MINLP & No \\
\hline [19] & Yes & Yes & No & ACOPF & RTP & MILP & No \\
\hline [20] & Yes & No & No & ACOPF & RTP & NLP & No \\
\hline [21] & No & No & No & ACOPF & Prices & MILP & No \\
\hline [22] & Yes & Yes & No & ACOPF & RTP & MILP & No \\
\hline
\end{tabular}


Table 1. Cont.

\begin{tabular}{|c|c|c|c|c|c|c|c|}
\hline Reference & $\begin{array}{l}\text { Demand } \\
\text { Response } \\
\text { Program }\end{array}$ & Elasticity & $\begin{array}{l}\text { Reliability } \\
\text { Issue }\end{array}$ & $\begin{array}{l}\text { Power } \\
\text { Flow }\end{array}$ & Pricing Method & Approach & $\begin{array}{c}\text { Bill Paid by } \\
\text { Customers }\end{array}$ \\
\hline [23] & Yes & Yes & No & ACOPF & Dynamic pricing & MILP & No \\
\hline [24] & Yes & Yes & No & ACOPF & RTP & MILP & Yes \\
\hline [25] & Yes & No & Yes & $\mathrm{ACOPF}$ & Prices & NLP & No \\
\hline [26] & Yes & No & No & ACOPF & TOU & MILP & Yes \\
\hline [27] & Yes & No & No & No & No & NLP & No \\
\hline [28] & No & No & Yes & ACOPF & RTP & NLP & No \\
\hline [29] & Yes & No & No & DCOPF & RTP & MILP & No \\
\hline [30] & Yes & No & No & No & No & Fuzzy model & No \\
\hline [31] & Yes & No & No & ACOPF & No & MILP & No \\
\hline$[32,35-40]$ & No & No & Yes & OPF & No & Monte Carlo simulation & No \\
\hline$[43,45,47]$ & No & No & Yes & ACOPF & No & Markov method & No \\
\hline$[46,48,49]$ & No & No & Yes & No & No & Monte Carlo simulation & No \\
\hline [51] & No & No & Yes & ACOPF & No & MINLP & No \\
\hline [52] & Yes & No & Yes & $\mathrm{ACOPF}$ & No & MILP & No \\
\hline [53] & No & No & Yes & ACOPF & No & Rollout algorithm & No \\
\hline [54] & No & No & No & No & No & PSO algorithm & No \\
\hline This paper & Yes & Yes & Yes & ACOPF & RTP & MILP & Yes \\
\hline
\end{tabular}

\subsection{Contributions}

One of the most important objectives of a DSO is to supply the required energy for the consumers and prevent outages to reduce energy not supplied, reduce the operation costs, and increase the consumers' satisfaction. Since device failure is inevitable, continuous and reliable distribution of electricity is impossible, and considering failure management in the form of detecting fault location and resolving it the shortest possible time is of great importance. Thus, a comprehensive model for examining reliability indices in a distribution network is required that decreases the operation costs and increases the consumers satisfaction. On the other hand, participation of consumers in the DR programs might prevent increasing electricity prices by the wholesale market at peak hours. In the models proposed in previous studies, DR programs reduced consumption at peak times, but these studies did not consider the simultaneous effect of DR and elasticity with a load restoration framework for improving the reliability indices, and they focused mainly on profitability for the DSO ([13-16,19-21]). Also, in some studies such as [46,48,54], the physical constraints of transmission lines were considered, or the effect of DSO on the energy market was neglected. Although, in some models, profitability for consumers and reduction in energy consumption costs were considered, dependency of energy consumption on the fluctuating prices of the electricity market, particularly at peak times, reduced the efficiency of these models. Also, these models did not represent the effect of load consumption and demand on changes of the reliability indices. Therefore, the purpose of this study was to formulate a novel method for instantaneous DR pricing, aiming to improve reliability of distribution networks. In the proposed framework, the energy consumption background for each consumer is used to obtain the base load curve. The price signals for the base load and real-time price are provided to the consumer by the DSO. The difference between the consumption and base load is considered in the consumers' invoices and recorded as the DSO revenue.

Since the real-time prices are uncertain, multiple scenarios were considered for RTP signals to specify the efficiency of the proposed framework. The model proposed for power system operation after linearization and conversion to MILP was solved using GAMS. In the proposed model, the load curve obtained using the reliability indices is calculated using a novel analytical method based on load restoration. The innovations of this paper are as follows: 
- presenting a new method for pricing based on basic load such that DR and elasticity are involved simultaneously;

- reducing the effect of electricity market price fluctuations on the consumption load curve;

- reducing computation time and volume;

- making usage of analytical reliability evaluation and load restoration methods practical;

- presenting a new mathematical method for hourly load curve and reducing the load peak;

- examining reliability and pricing tariffs simultaneously;

- calculating consumers' invoice with a new tariff that increases consumer satisfaction with participation in DR programs.

\section{The Energy Consumption Invoice Model for the Proposed Tariff}

The energy consumption invoice for the proposed RTP tariffs is modeled as follows:

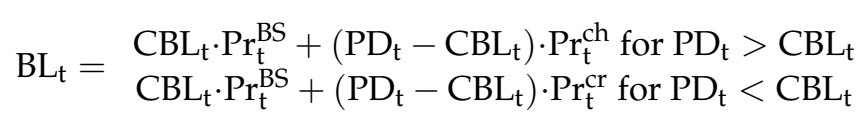

In this equation, $\mathrm{BL}_{\mathrm{t}}$ is the energy consumption cost of the participant at time $\mathrm{t}, \mathrm{CBL}_{\mathrm{t}}$ is the customer baseline load of the participant, $\mathrm{Pr}_{t}^{\mathrm{BS}}$ is the baseline rate, $\mathrm{Pr}_{t}^{\mathrm{Ch}}$ is the charge rate, $\mathrm{Pr}_{t}^{\mathrm{Cr}}$ is the credit rate, and $\mathrm{PD}_{t}$ is the hourly energy consumption of the participant. If the load consumption is higher than CBL, the energy consumption cost is calculated with $\mathrm{Pr}_{t}^{\mathrm{Ch}}$. When the load consumption is less than CBL, the difference of $\mathrm{PD}_{\mathrm{t}}$ with CBL is negative; thus, the energy consumption cost of the participant decreases with the rate of $\mathrm{Pr}_{\mathrm{t}}^{\mathrm{Cr}}$. To calculate a customer's invoice in one operation day, the customer's data and the final prices of that day are collected, and the invoice is calculated at the end of the day.

$$
\mathrm{BL}^{\text {Total }}=\sum_{\mathrm{t}=1}^{24} \mathrm{BL}_{\mathrm{t}}
$$

\subsection{Definition of Consumption Peak and Nonpeak}

The tariff defines certain hours of the day as the peak consumption time. When there is a shortage of generation capacity in the market, energy generation companies can dramatically increase the energy price in the market. The instantaneous pricing tariff in such conditions provides the possibility for consumers to participate in DR programs and change the real-time market (RTM) price. In other words, consumers can reduce the electricity price at peak times (due to consumption decrease) by reducing their consumption at peak times and shifting their consumption to nonpeak times. By defining a binary variable with peak and nonpeak hours, the tariff is determined as follows:

$$
\mathrm{q}_{\mathrm{t}}= \begin{cases}1 & \operatorname{Pr}_{\mathrm{t}}^{\mathrm{M}}>\operatorname{Pr}_{\mathrm{t}}^{\mathrm{BS}} \\ 0 & \operatorname{Pr}_{\mathrm{t}}^{\mathrm{M}}<\operatorname{Pr}_{\mathrm{t}}^{\mathrm{BS}}\end{cases}
$$

In this equation, $\mathrm{q}_{t}$ is the consumption peak hour, $\operatorname{Pr}_{t}^{B S}$ is the baseline price that is announced to the consumer one day ahead, and $\mathrm{Pr}_{t}^{\mathrm{M}}$ is the instantaneous energy price in the real-time market equal to marginal price. The proposed tariff increases $\operatorname{Pr}_{t}^{C r}$ at the peak hour. As this price increases, the credit of load reduction at the peak hour increases. At these hours, $\mathrm{Pr}_{t}^{\mathrm{Cr}}$ is known and equal to the instantaneous market price.

$$
\mathrm{q}_{\mathrm{t}}=1 \quad \operatorname{Pr}_{\mathrm{t}}^{\mathrm{Cr}}>\operatorname{Pr}_{\mathrm{t}}^{\mathrm{M}} \quad \operatorname{Pr}_{\mathrm{t}}^{\mathrm{Ch}}=\operatorname{Pr}_{\mathrm{t}}^{\mathrm{M}}
$$

The proposed tariff at nonpeak hours, when $\mathrm{q}_{\mathrm{t}}$ is zero, considers $\mathrm{Pr}_{\mathrm{t}}^{\mathrm{Ch}}$ lower than the market price. Thus, more discount is considered for increasing energy consumption at lowload hours. At these hours, $\mathrm{Pr}_{\mathrm{t}}^{\mathrm{Cr}}$ is equal to its baseline value (the real-time market price).

$$
\mathrm{q}_{\mathrm{t}}=0 \quad \operatorname{Pr}_{\mathrm{t}}^{\mathrm{Ch}}<\operatorname{Pr}_{\mathrm{t}}^{\mathrm{M}} \quad \operatorname{Pr}_{\mathrm{t}}^{\mathrm{Cr}}=\operatorname{Pr}_{\mathrm{t}}^{\mathrm{M}}
$$


This tariff was aimed to provide the possibility for customers to respond to different market conditions by providing instantaneous energy prices. By reducing energy consumption at peak hours, the possibility of applying power is taken from companies, and the energy price and its fluctuations are reduced. This tariff was aimed to motivate customers to consume more optimally by increasing the credit given to consumption reduction at peak hours and the discounts given to consumption increase at other times. This tariff assigns more credit to load reduction at peak hours without increasing the costs of load increase. On the other hand, at low-load hours, it gives greater discounts to consumption increases without increasing the credit of consumption reduction. In other words, the incentive offered to the customers with optimal costs increases effectively. In the following sections, the proposed tariff is added to the DS operation model to calculate the demand curve.

\subsection{The Load Model Participating in the Proposed Tariff}

Since in the proposed tariff, two prices of $\operatorname{Pr}_{t}^{C r}$ and $\operatorname{Pr}_{t}^{C h}$ are considered for upper and lower marginal consumptions in addition to the baseline price, modeling the vector of change in electricity price ( $\Delta \mathrm{Pr}$ ) becomes complicated. Considering Equation (1), which models the hourly energy consumption cost, it can be concluded that when load is lower than CBL, the energy consumption cost decreases as $\mathrm{Pr}_{t}^{\mathrm{Cr}}$ increases. In other words, when $\mathrm{q}_{\mathrm{t}}$ is one (at the peak hour of consumption), the energy price is higher than the baseline price and the load consumption is lower than the baseline consumption. Also, when consumption load is higher than CBL, the energy consumption cost decreases as $\operatorname{Pr}_{t}^{C h}$ decreases. By implementing the proposed tariff and motivating customers to consume optimally, the load reduction at peak times and load increase at other times is reinforced. Therefore, $\Delta \operatorname{Pr}$ can be modeled as follows:

$$
\Delta \operatorname{Pr}=\operatorname{Pr}_{t}^{\mathrm{M}}-\operatorname{Pr}_{t}^{B s}+\left(\operatorname{Pr}_{t}^{C r}-\operatorname{Pr}_{t}^{M}\right) \cdot q_{t}+\left(\operatorname{Pr}_{t}^{C h}-\operatorname{Pr}_{t}^{M}\right) \cdot\left(1-q_{t}\right)
$$

In the baseline case, prices of $\operatorname{Pr}_{t}^{C r}$ and $\operatorname{Pr}_{t}^{C h}$ are the same as the marginal price $\left(\operatorname{Pr}_{t}^{\mathrm{M}}\right)$; therefore, this relationship is simplified as follows:

$$
\Delta \operatorname{Pr}=\operatorname{Pr}_{t}^{M}-\operatorname{Pr}_{t}^{B s}
$$

In this tariff, the base price is already known, and the marginal price is announced to the consumer on the operation day. Of course, predicting the price announced the day before helps the consumer to plan. Energy invoice is directly proportional to $\mathrm{Pr}_{\mathrm{t}}^{\mathrm{M}}$; thus, when $\operatorname{Pr}_{t}^{\mathrm{M}}$ exceeds $\operatorname{Pr}_{t}^{\mathrm{Bs}}$, the customer reduces their consumption, and when $\operatorname{Pr}_{t}^{\mathrm{M}}$ becomes lower than $\operatorname{Pr}_{t}^{\mathrm{Bs}}$, the customer increases their consumption. Now, the following linear relationship can be used to calculate the relative load changes $(\triangle \mathrm{PD})$ in response to relative price changes:

$$
\left(\begin{array}{c}
\Delta \mathrm{PD}_{1} \\
\cdot \\
\cdot \\
\cdot \\
\Delta \mathrm{PD}_{24}
\end{array}\right)=\zeta \cdot\left(\begin{array}{ccccc}
\varepsilon_{1,1} & \cdot & \cdot & \cdot & \varepsilon_{1,24} \\
\cdot & \cdot & & \cdot \\
\cdot & & \cdot & & \cdot \\
\cdot & & & \cdot & \cdot \\
\varepsilon_{24,1} & \cdot & \cdot & \cdot & \varepsilon_{24,24}
\end{array}\right)\left(\begin{array}{c}
\Delta \operatorname{Pr}_{1} \\
\cdot \\
\cdot \\
\cdot \\
\Delta \operatorname{Pr}_{24}
\end{array}\right)
$$

in which $\varepsilon_{1,1}$ is the load elasticity coefficient in response to relative price changes of the proposed tariff, and $\zeta$ is the customers' enrollment level in the DR program. In the proposed tariff, marginal consumption is subject to variable prices. Using the demand response model for the proposed tariff, the participants' behavior in response to prices is predictable.

\subsection{Operation Considering the Proposed Scheme}

The proposed pricing tariff is a three-sectional tariff based on consumption basic load. This tariff uses three different rates to calculate the energy consumption at each hour. One of these rates is known from the previous day and does not change. This rate is called the 
baseline rate. Predictions for the two other rates for each hour of the operation day are announced to the customer on the previous day, but their exact values are announced to the customer a few hours before the operation day. The customer's energy cost at each hour up to CBL is calculated with the baseline rate. Energy consumptions higher than CBL are calculated with a rate called the charge rate, and energy consumptions lower than CBL are calculated with the credit rate. This tariff can control the credit and discount given to the customer by offering different rates for consumptions higher and lower than CBL. This property of the proposed tariff increases the number of participants in the tariff and increases motivation for optimal consumption. By increasing the efficiency of the tariff, the company makes more profit, and the customer saves more. This optimal tariff covers its implementation costs and reduces operation costs also.

\subsection{The Objective Function}

In this section, the profit model of the DSO is developed as the objective function considering the proposed tariff. The invoice paid by the customers is calculated as the total invoice paid by each type of customer. The bill is modeled as follows:

$$
\mathrm{BL}_{\mathrm{t}}^{\text {Total }}=\sum_{\mathrm{t}=1}^{24} \sum_{\mathrm{j}=1}^{\mathrm{n}} \mathrm{BL}_{\mathrm{t}, \mathrm{j}}
$$

In this equation, $\mathrm{BL}_{\mathrm{t}}^{\text {Total }}$ is the bill paid by the customer $\mathrm{n}$ at time $\mathrm{t}$, and $\mathrm{j}$ is a set of three different industrial, commercial, and residential customers. To calculate the cost of energy consumption for the whole operating day, the product of energy consumption per hour by the energy price at the same hour is calculated as follows:

$$
\mathrm{BL}_{\mathrm{t}}^{\text {Total }}=\sum_{\mathrm{t}=1}^{24}\left[\mathrm{Pr}_{\mathrm{t}}^{\mathrm{M}} \cdot \mathrm{PD}_{\mathrm{t}}\right]
$$

This invoice model is used for a single-part tariff (present RTP), and the invoice model for a two-part tariff (proposed RTP) is as follows:

$$
\mathrm{BL}_{\mathrm{t}}^{\text {Total }}=\sum_{\mathrm{t}=1}^{24}\left[\mathrm{Pr}_{\mathrm{t}}^{\mathrm{Bs}} \cdot \mathrm{CBL}_{\mathrm{t}}+\mathrm{Pr}_{\mathrm{t}}^{\mathrm{M}} \cdot\left(\mathrm{PD}_{\mathrm{t}}-\mathrm{CBL}_{\mathrm{t}}\right)\right]
$$

The energy consumption should be obtained to calculate the invoice. The demand of the customers that participate in the DR program is represented by $\mathrm{CBL}_{\mathrm{C}}$ :

$$
\mathrm{CBL}_{\mathrm{C}}=\mathrm{DR} \cdot \mathrm{CBL}_{\mathrm{t}}
$$

in which DR is the load participation in the demand response. According to Equation (8), the load changes vector is calculated as follows:

$$
\Delta \mathrm{PD}=\zeta \cdot \mathrm{E}_{\mathrm{C}} \cdot \Delta \mathrm{Pr}
$$

in which $\Delta \operatorname{Pr}$ is the price changes vector, $\mathrm{E}_{\mathrm{C}}$ is the elasticity, and $\zeta$ is the customers' enrollment level in the DR program. Assuming that the demand curve is linear around the operation point, the load elasticity is defined as follows:

$$
\mathrm{E}_{\mathrm{C}}^{\mathrm{j}, \mathrm{t}}=\frac{\Delta \mathrm{PD}_{\mathrm{j}, \mathrm{t}}}{\Delta \mathrm{Pr}_{\mathrm{j}, \mathrm{t}}} \cdot \frac{\operatorname{Pr}_{\mathrm{j}, \mathrm{t}}^{\mathrm{int}}}{\mathrm{PD}_{\mathrm{j}, \mathrm{t}}^{\mathrm{int}}}
$$

in which $\mathrm{PD}_{\mathrm{j}}^{\mathrm{int}}$ is the demand of customer $\mathrm{j}$ at time $\mathrm{t}$ before implementing the DR program and $\operatorname{Pr}_{j}^{\text {int }}$ is the initial value of the electricity price offered to customer $j$ at time $t$. The 
modified load characteristics of the customer under the proposed scheme are calculated using the following equation:

$$
\mathrm{PD}_{\mathrm{t}}=\mathrm{CBL}_{\mathrm{t}}+\Delta \mathrm{PD}_{\mathrm{t}}
$$

in which PD represents the power consumption vector of the customer under the proposed scheme. Accordingly, the total load of the distribution system can be calculated as follows:

$$
\mathrm{PD}_{\mathrm{t}}=\mathrm{PD}_{\mathrm{DR}}+\mathrm{PD}_{\mathrm{NDR}}
$$

in which $\mathrm{PD}_{\mathrm{DR}}$ is the set of customers that participate in the proposed scheme, and $\mathrm{PD}_{\mathrm{NDR}}$ is the set of customers that do not participate in the proposed scheme and remain as default. According to Equations (15) and (16), the final demand of the customer is calculated as follows. Accordingly, considering the responsive and nonresponsive loads, the total load of the DS is calculated as follows:

$$
\mathrm{PD}_{\mathrm{t}}=\left(\mathrm{CBL}_{\mathrm{C}}-\Delta \mathrm{PD}\right)+(1-\mathrm{DR}) \cdot \mathrm{CBL}_{\mathrm{t}}
$$

The first part of Equation (17), $\left(\mathrm{CBL}_{C}-\triangle \mathrm{PD}\right)$, is the final demand of the customers that participate in the DR. The second part is the demand of the customers that do not participate in the DR. Therefore, the final objective function is defined as follows:

$$
\mathrm{P}^{\text {Daily }}=\sum_{\mathrm{j}=1}^{3}\left(\mathrm{BL}_{\mathrm{j}}^{\text {Total }}-\mathrm{C}_{\mathrm{t}}^{\text {Total }}\right)
$$

In this equation, $\mathrm{P}^{\text {Daily }}$ is the DSO profit from daily operation. $\mathrm{BL}_{\mathrm{j}}^{\text {Total }}$ is the total bill received from all customers at time $t$, comprising the DSO income. $C_{t}^{\text {Total }}$ is the cost of supplying the DS energy at a specific hour, which includes the cost of buying energy from the station, the cost of buying energy from DGs, and the cost of buying interruptible contracts for covering emergency conditions. $\mathrm{P}^{\text {Daily }}$ is the daily profit of the DSO, obtained from total profit at each hour over the operation period. The total operation cost is calculated as follows:

$$
C_{t}^{\text {Total }}=\operatorname{Pr}_{t}^{\mathrm{M}} \cdot P_{t}^{\text {Grid }}+\sum_{g=1}^{\mathrm{N}_{\mathrm{DG}}} \mathrm{C}_{\mathrm{t}, \mathrm{g}}^{\mathrm{DG}}+\operatorname{Pr}_{\mathrm{t}}^{\mathrm{IL}} \cdot \mathrm{P}_{\mathrm{t}}^{\mathrm{IL}, \mathrm{C}}+\mathrm{C}_{\mathrm{t}}^{\mathrm{ET}}
$$

In this equation, $\mathrm{P}_{t}^{\text {Grid }}$ is the purchased power from grid at each hour and $\mathrm{Pr}_{t}^{\mathrm{IL}}$ is the real-time price of interruptible loads. We considered $\operatorname{Pr}_{t}^{\mathrm{IL}}$ to be $10 \%$ of the real-time price of purchasing electricity from the grid according to [3]. $\mathrm{P}_{\mathrm{t}}^{\mathrm{IL}, \mathrm{C}}$ is the interruptible load contract, interruptible loads being those that participate in the interruptible/curtailable program. In this method, the consumers make an agreement with the operator to decrease their consumption whenever the operator requests. The customers that participate in this program receive credit and discounts for reducing their consumption when failures occur, and the customers who do not reduce their consumption when required are penalized. This program is more suitable for industrial and large commercial loads. The loads that participate in this program vary from $200 \mathrm{~kW}$ to $3 \mathrm{MW}$. This range might be different in different markets and conditions. $\mathrm{C}_{\mathrm{t}}^{\mathrm{ET}}$ is the cost of using the smart measurement infrastructure, $\mathrm{N}_{\mathrm{DG}}$ is total number of the DG units in the system, and $\mathrm{C}_{\mathrm{t}, \mathrm{g}}^{\mathrm{DG}}$ is the piecewise linear cost function of energy generation by DGs, which is estimated using the following equation.

$$
\mathrm{C}_{\mathrm{t}, \mathrm{g}}^{\mathrm{DG}}=\mathrm{C}_{\mathrm{t}, \mathrm{g}}^{\mathrm{SU}}+\mathrm{C}_{\mathrm{g}}^{\mathrm{M}} \cdot \mathrm{I}_{\mathrm{t}, \mathrm{g}}+\sum_{\mathrm{n}=1} \mathrm{r}_{\mathrm{n}, \mathrm{g}} \mathrm{P}_{\mathrm{t}, \mathrm{n}, \mathrm{g}}
$$

in which $C_{t, g}^{S U}, C_{g}^{M}, I_{t, g}, r_{n, g}$, and $P_{t, n, g}$ are the start-up cost of DG unit $g$ in real-time, the minimum generation cost of unit $\mathrm{g}$, a binary variable denoting commitment status of 
DG unit $g$ at time $t$, the linear generation cost model parameter of DG $g$, and the power generation for DG $\mathrm{g}$ for segment $\mathrm{n}$ of the piecewise linear cost function, respectively.

\subsection{Constraints}

The power balance relationship is modeled as follows:

$$
\begin{gathered}
P_{t}^{G r i d}+\sum_{g=1}^{N D G} P_{t, g}^{D G}-P D_{t}^{R T}+P_{t}^{I L . C}=\sum_{k, r} L F_{k, r, t}^{P} \\
Q_{t}^{\text {Grid }}+\sum_{\mathrm{g}=1}^{N D G} Q_{t, g}^{D G}-Q_{t}^{R T}+Q_{t}^{I L . C}=\sum_{k, r} L_{k, r, t}^{Q}
\end{gathered}
$$

In the above equations, $\mathrm{PD}_{\mathrm{t}}^{\mathrm{RT}}$ and $\mathrm{QD}_{\mathrm{t}}^{\mathrm{RT}}$ are the active and reactive power consumed by customers in period $t$, respectively; $P_{t, g}^{D G}$ and $Q_{t, g}^{D G}$ are the active and reactive power generated by each DG unit, respectively; and $\mathrm{LF}_{\mathrm{k}, \mathrm{r}, \mathrm{t}}^{\mathrm{P}}$ and $\mathrm{LF}_{\mathrm{k}, \mathrm{r}, \mathrm{t}}^{\mathrm{Q}}$ are the active and reactive power flow, respectively, from bus $k$ to bus $r$ at time $t$ [24]:

$$
\begin{gathered}
\mathrm{LF}_{\mathrm{k}, \mathrm{r}, \mathrm{t}}^{\mathrm{P}}=\left[\begin{array}{c}
\mathrm{G}_{\mathrm{k}, \mathrm{r}}\left[\mathrm{V}_{\mathrm{k}, \mathrm{t}}^{2}-\mathrm{V}_{\mathrm{k}, \mathrm{t}} \cdot \mathrm{V}_{\mathrm{r}, \mathrm{t}} \cdot \cos \left(\delta_{\mathrm{k}, \mathrm{t}}-\delta_{\mathrm{r}, \mathrm{t}}\right)\right] \\
-\mathrm{B}_{\mathrm{k}, \mathrm{r}} \cdot \mathrm{V}_{\mathrm{k}, \mathrm{t}} \cdot \mathrm{V}_{\mathrm{r}, \mathrm{t}} \cdot \sin \left(\delta_{\mathrm{k}, \mathrm{t}}-\delta_{\mathrm{r}, \mathrm{t}}\right)
\end{array}\right] \\
\mathrm{LF}_{\mathrm{k}, \mathrm{r}, \mathrm{t}}^{\mathrm{Q}}=-\left[\begin{array}{c}
\mathrm{B}_{\mathrm{k}, \mathrm{r}}\left[\mathrm{V}_{\mathrm{k}, \mathrm{t}}^{2}-\mathrm{V}_{\mathrm{k}, \mathrm{t}} \cdot \mathrm{V}_{\mathrm{r}, \mathrm{t}} \cdot \cos \left(\delta_{\mathrm{k}, \mathrm{t}}-\delta_{\mathrm{r}, \mathrm{t}}\right)\right] \\
+\mathrm{G}_{\mathrm{k}, \mathrm{r}} \cdot \mathrm{V}_{\mathrm{k}, \mathrm{t}} \cdot \mathrm{V}_{\mathrm{r}, \mathrm{t}} \cdot \sin \left(\delta_{\mathrm{k}, \mathrm{t}}-\delta_{\mathrm{r}, \mathrm{t}}\right)
\end{array}\right]
\end{gathered}
$$

in which $V_{k, t}\left(\delta_{k, t}\right)$ and $G_{k, r}\left(B_{k, r}\right)$ are the voltage magnitude (voltage angle) at node $k$ at time $t$ and the line conductance (susceptance) from bus $k$ to $r$, respectively. The two above equations are nonlinear; they were linearized through proper approximation [24].

$$
\begin{gathered}
\mathrm{LF}_{\mathrm{k}, \mathrm{r}, \mathrm{t}}^{\mathrm{P}}=\mathrm{G}_{\mathrm{k}, \mathrm{r}}\left(\mathrm{V}_{\mathrm{k}, \mathrm{t}}-\mathrm{V}_{\mathrm{r}, \mathrm{t}}-\mathrm{W}_{\mathrm{k}, \mathrm{r}, \mathrm{t}}+1\right)-\mathrm{B}_{\mathrm{k}, \mathrm{t}} \cdot\left(\delta_{\mathrm{k}, \mathrm{t}}-\delta_{\mathrm{r}, \mathrm{t}}\right) \\
\mathrm{LF}_{\mathrm{k}, \mathrm{r}, \mathrm{t}}^{\mathrm{Q}}=-\mathrm{B}_{\mathrm{k}, \mathrm{r}}\left(\mathrm{V}_{\mathrm{k}, \mathrm{t}}-\mathrm{V}_{\mathrm{r}, \mathrm{t}}-\mathrm{W}_{\mathrm{k}, \mathrm{r}, \mathrm{t}}+1\right)-\mathrm{G}_{\mathrm{k}, \mathrm{t}} \cdot\left(\delta_{\mathrm{k}, \mathrm{t}}-\delta_{\mathrm{r}, \mathrm{t}}\right) \\
\left|\left(\delta_{\mathrm{k}, \mathrm{t}}-\delta_{\mathrm{r}, \mathrm{t}}\right)\right| \leq 10^{\mathrm{o}} \\
\mathrm{W}_{\mathrm{k}, \mathrm{r}, \mathrm{t}}=\mathrm{d}_{\mathrm{k}, \mathrm{r}, \mathrm{t}, \mathrm{m}} \cdot\left(\delta_{\mathrm{k}, \mathrm{t}}-\delta_{\mathrm{r}, \mathrm{t}}\right)+\mathrm{e}_{\mathrm{k}, \mathrm{r}, \mathrm{t}, \mathrm{m}}
\end{gathered}
$$

Linearizing power flow equations was given in [24]. In this reference, the linearization error was neglected, and $\left(\left|\left(\delta_{\mathrm{k}, \mathrm{t}}-\delta_{\mathrm{r}, \mathrm{t}}\right)\right| \leq 10^{\circ}\right)$ was considered to obtain the linear estimation for $\cos \left(\delta_{k, t}-\delta_{r, t}\right)$. This reduces computation time significantly. In the above equation, $\mathrm{W}_{\mathrm{k}, \mathrm{r}, \mathrm{t}}$ describes the linear approximation of $\cos \left(\delta_{\mathrm{k}, \mathrm{t}}-\delta_{\mathrm{r}, \mathrm{t}}\right)$, and $\mathrm{e}_{\mathrm{k}, \mathrm{r}, \mathrm{t}, \mathrm{m}}$ and $\mathrm{d}_{\mathrm{k}, \mathrm{r}, \mathrm{t}, \mathrm{m}}$ are the linearization constants. The constraints of active and reactive power flow and phase angle are considered as follows [24]:

$$
\begin{gathered}
-\overline{\mathrm{LF}_{\mathrm{k}, \mathrm{r}, \mathrm{t}}^{\mathrm{P}}} \leq \mathrm{LF}_{\mathrm{k}, \mathrm{r}, \mathrm{t}}^{\mathrm{P}} \leq \overline{\mathrm{LF}_{\mathrm{k}, \mathrm{r}, \mathrm{t}}^{\mathrm{P}}} \\
-\overline{\mathrm{LF}_{\mathrm{k}, \mathrm{r}, \mathrm{t}}^{\mathrm{Q}}} \leq \mathrm{LF}_{\mathrm{k}, \mathrm{r}, \mathrm{t}}^{\mathrm{Q}} \leq \overline{\mathrm{LF}_{\mathrm{k}, \mathrm{r}, \mathrm{t}}^{\mathrm{Q}}} \\
-\pi \leq \delta_{\mathrm{k}, \mathrm{t}} \leq \pi
\end{gathered}
$$

DG constraints: the operation of a DG unit is subject to some technical limits, including generation limits, minimum down/up time, and ramp-down/ramp-up constraints. The DG power constraints considering the participation of the units are modeled as follows:

$$
\begin{aligned}
& \mathrm{P}_{\mathrm{t}, \mathrm{n}, \mathrm{g}} \leq \mathrm{P}_{\mathrm{n}, \mathrm{g}}^{\text {DGSegMax }} \cdot \mathrm{I}_{\mathrm{t}, \mathrm{g}} \\
& \mathrm{C}_{\mathrm{t}, \mathrm{g}}^{\mathrm{SU}}=\mathrm{Z}_{\mathrm{g}}\left(\mathrm{I}_{\mathrm{t}, \mathrm{g}}-\mathrm{I}_{\mathrm{t}-1, \mathrm{~g}}\right)
\end{aligned}
$$




$$
\mathrm{P}_{\mathrm{t}, \mathrm{g}}^{\mathrm{DG}}=\mathrm{P}_{\mathrm{g}}^{\mathrm{DGmin}} \mathrm{I}_{\mathrm{t}, \mathrm{g}}+\sum_{\mathrm{n}=1} \mathrm{P}_{\mathrm{t}, \mathrm{n}, \mathrm{g}}
$$

In the above equations, $\mathrm{P}_{\mathrm{n}, \mathrm{g}}^{\mathrm{DGSegMax}}, \mathrm{P}_{\mathrm{g}}^{\mathrm{DGmin}}$, and $\mathrm{Z}_{\mathrm{g}}$ are the maximum capacity of DG generation segment, the minimum DG capacity limit for active power, and the DG start-up cost parameter, respectively. The generation constraints ensure that the power generated by each DG unit is bounded by the corresponding upper and lower limits as follows:

$$
\mathrm{P}_{\mathrm{g}}^{\mathrm{DGmin}} \cdot \mathrm{I}_{\mathrm{t}, \mathrm{g}}<\mathrm{P}_{\mathrm{t}, \mathrm{g}}^{\mathrm{DG}}<\mathrm{P}_{\mathrm{g}}^{\mathrm{DGMax}} \cdot \mathrm{I}_{\mathrm{t}, \mathrm{g}}
$$

in which $\mathrm{P}_{\mathrm{g}}^{\mathrm{DGMax}}$ is the maximum DG capacity limit for active power. The generation of DG units should adhere to the ramp-down/-up constraints as follows:

$$
\left\{\begin{array}{l}
\mathrm{P}_{\mathrm{t}+1, \mathrm{~g}}^{\mathrm{DG}}-\mathrm{P}_{\mathrm{t}, \mathrm{g}}^{\mathrm{DG}} \leq \mathrm{R}_{\mathrm{g}}^{\mathrm{UP}} \mathrm{t}=0,1, \ldots, \mathrm{t}-1 \\
\mathrm{P}_{\mathrm{t}, \mathrm{g}}^{\mathrm{DG}}-\mathrm{P}_{\mathrm{t}+1, \mathrm{~g}}^{\mathrm{DG}} \leq \mathrm{R}_{\mathrm{g}}^{\mathrm{Dn}} \mathrm{t}=0,1, \ldots, \mathrm{t}-1 \\
\left.\mathrm{P}_{\mathrm{t}, \mathrm{g}}^{\mathrm{DG}}\right|_{\mathrm{t}=0}=0
\end{array}\right.
$$

In the above equations, $\mathrm{R}_{\mathrm{g}}^{\mathrm{UP}}$ and $\mathrm{R}_{\mathrm{g}}^{\mathrm{Dn}}$ are the ramp-up/down limits for DG unit $\mathrm{g}$.

Minimum down-/uptime constraints guarantee that the operating status of DG units adheres to the limits as follows:

$$
\left\{\begin{array}{l}
\sum_{1=1}^{\mathrm{MUP}_{\mathrm{g}}} \mathrm{I}_{\mathrm{t}-1+1, \mathrm{~g}} \geq \mathrm{MUP}_{\mathrm{g}} \\
\sum_{\mathrm{l}=1}^{\mathrm{MDN}_{\mathrm{g}}}\left(1-\mathrm{I}_{\mathrm{t}-1+1, \mathrm{~g}}\right) \geq \mathrm{MDN}_{\mathrm{g}}
\end{array}\right.
$$

in which $\mathrm{MUP}_{\mathrm{g}}$ and $\mathrm{MDN}_{\mathrm{g}}$ are the minimum up- and downtime of the DG unit, respectively. The bus voltage limits are taken into account as follows:

$$
-\mathrm{V} \leq \mathrm{V}_{\mathrm{t}} \leq \overline{\mathrm{V}}
$$

in which $\mathrm{V}$ and $\overline{\mathrm{V}}$ are the minimum and maximum values of allowed voltage magnitudes, respectively.

The power constraint received from the network and voltage of phases is modeled as follows:

$$
\mathrm{P}_{\mathrm{t}}^{\mathrm{Grid}} \leq \mathrm{P}^{\mathrm{Grid}, \text { Max }}
$$

In this equation, $\mathrm{P}^{\mathrm{Grid}, \mathrm{Max}}$ is the maximum real power flowing through the distribution transformer.

\subsection{MILP Formulation}

Finally, the original DSO profit optimization problem can be recast by the following MILP:

$$
\begin{aligned}
\operatorname{Max} . \sum_{j=1}^{3}\left\{\left(\sum_{t=1}^{24}\left[\operatorname{Pr}_{t}^{\mathrm{Bs}} \cdot \mathrm{CBL}_{\mathrm{t}}+\operatorname{Pr}_{\mathrm{t}}^{\mathrm{M}} \cdot\left(\mathrm{PD}_{\mathrm{t}}-\mathrm{CBL}_{\mathrm{t}}\right)\right]\right)\right. \\
\left.-\left(\operatorname{Pr}_{\mathrm{t}}^{\mathrm{M}} \cdot \mathrm{P}_{\mathrm{t}}^{\mathrm{Grid}}+\sum_{\mathrm{g}=1}^{\mathrm{N}_{\mathrm{DG}}} \mathrm{C}_{\mathrm{t}, \mathrm{g}}^{\mathrm{DG}}+\mathrm{Pr}_{\mathrm{t}}^{\mathrm{IL}} \cdot \mathrm{P}_{\mathrm{t}}^{\mathrm{IL}, \mathrm{C}}+\mathrm{C}_{\mathrm{t}}^{\mathrm{ET}}\right)\right\}
\end{aligned}
$$

Subject to:

Equations (19)-(22), and Equations (25)-(39)

The variables associated with this problem are $\left\{Q_{t}^{G r i d}, Q_{t, g}^{D G}, C_{t, g}^{D G}, C_{t, g}^{S U}, P_{t, n, g}, L F_{k, r, t}^{P}\right.$ $\left.\mathrm{LF}_{\mathrm{k}, \mathrm{r}, \mathrm{t}}^{\mathrm{Q}}, \mathrm{V}_{\mathrm{k}, \mathrm{t}}, \mathrm{V}_{\mathrm{r}, \mathrm{t}}, \mathrm{W}_{\mathrm{k}, \mathrm{r}, \mathrm{t}}, \delta_{\mathrm{k}, \mathrm{t}}, \delta_{\mathrm{r}, \mathrm{t}}, \mathrm{I}_{\mathrm{t}, \mathrm{g}}\right\}$, and the positive variables are $\left\{\mathrm{P}_{\mathrm{t}}^{\mathrm{Grid}}, \mathrm{P}_{\mathrm{t}, \mathrm{g}}^{\mathrm{DG}}, \mathrm{P}_{\mathrm{t}}^{\mathrm{IL} . \mathrm{C}}, \mathrm{Q}_{\mathrm{t}}^{\mathrm{IL} . \mathrm{C}}\right\}$. 


\section{Effect of the Proposed Pricing Tariff on DS Reliability}

Quantifying the advantages of employing DR for cost studies is essential. In this section, a method is presented for accurate calculation of the effect of implementing DR and describing it as DS reliability indices. In this paper, it was assumed that the daily energy consumption of each customer was fixed. Also, customers' behavior was optimal; customers transferred their consumption from peak hours to nonpeak hours in response to the proposed tariff. Therefore, implementing the proposed program did not affect the average daily energy of the DS and only decreased the load peak. The general algorithm of the method proposed in this paper is shown in Figure 1.

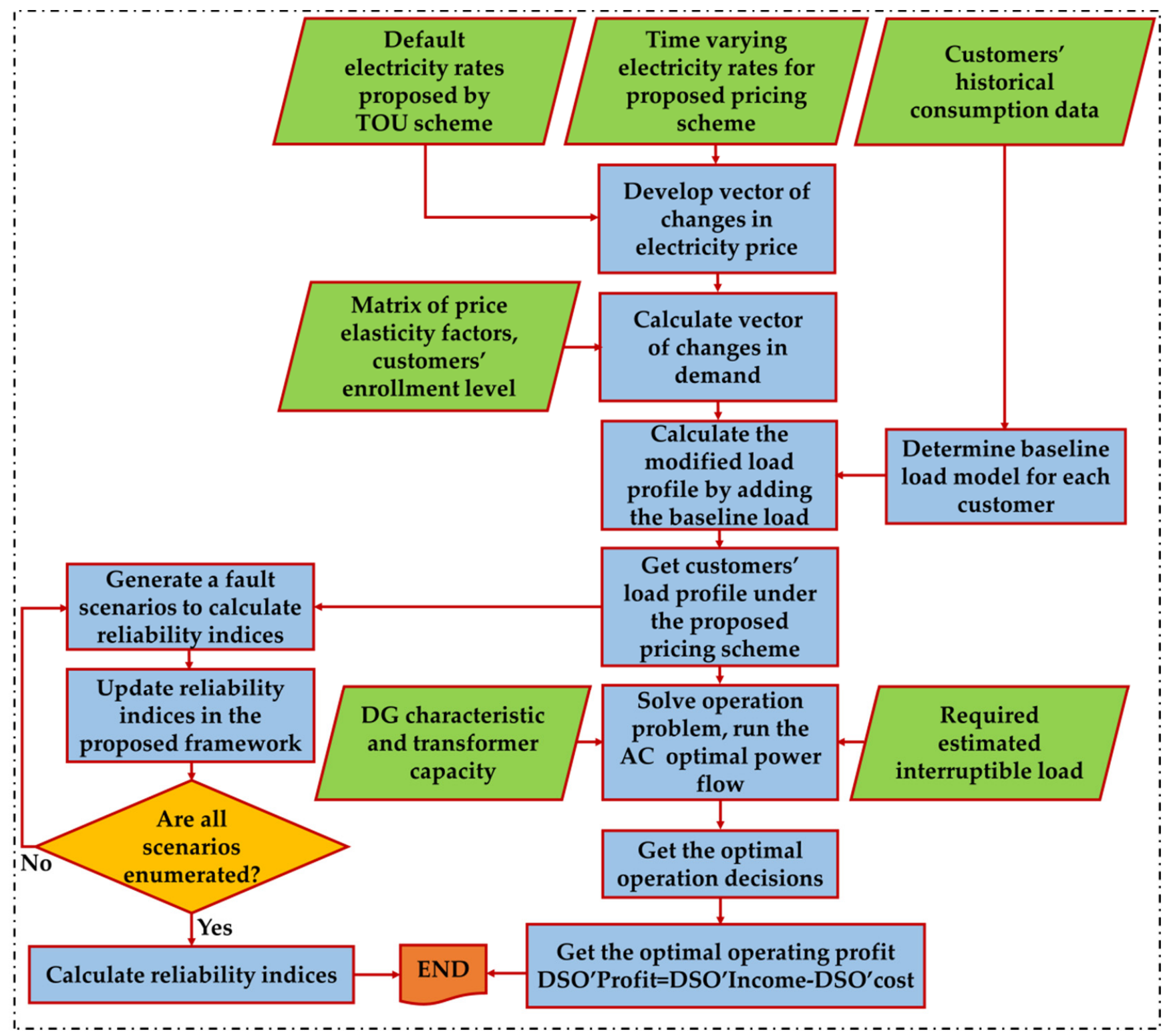

Figure 1. The general algorithm of the proposed method.

\subsection{Effect of Load Transfer on System Reliability}

Many distribution systems have open points in their ring structure such that they operate as effective radial systems under natural conditions, but when a fault occurs in a system, some switches are closed, and a number of loads that are interrupted are restored. This property affects DS reliability because other loads that are disconnected until the faulty element is repaired completely are returned to normal conditions during the switching 
time using these links. Since many distribution system faults occur during peak hours, all disconnected loads cannot be transferred to the side feeders via the normal lines, because the side feeder might be overloaded or because connecting all loads to the side feeder reduces the voltage significantly. In such conditions, the time for which a load point is disconnected, which corresponds to a failure, is equivalent to the isolation time if it can be transferred to the side feeder or equivalent to the maintenance time if it cannot be transferred to the side feeder. The average of these two values specifies the time for which a load is disconnected as a result of a fault. Also, recovering disconnected loads by connecting to the side feeder increases by decreasing energy consumption at peak times, and more loads are thereby recovered $[55,56]$. Hence, the expected energy-not-supplied index decreases [57].

\subsection{DS Reliability Indices}

The reliability indices were mainly calculated based on random construction of the fault time or correctness of each element instead of generating a faulty or healthy sequence of an element. The main reliability indices in the distribution system that were defined for each load point included the average failure rate $\lambda_{i}$, the average disconnection time $r_{i}$, and the average annual disconnection time $U_{i}$.

Customer-Based Indices

These indices consider the number of customers at each load point. The average time on the primary indices is considered using the number of customers. Some of these indices include $[55,56]$ :

- $\quad$ System average interruption frequency index (SAIFI), the average number of customer interruptions in a system divided by the total number of customers in the period of study:

$$
\text { SAIFI }=\frac{\sum_{\mathrm{i}=1}^{\mathrm{n}} \lambda_{\mathrm{i}} \cdot \mathrm{N}_{\mathrm{i}}}{\sum_{\mathrm{i}=1}^{\mathrm{n}} \mathrm{N}_{\mathrm{i}}}
$$

in which $\lambda_{i}$ is the number of interruptions per year and $N_{i}$ is the number of customers of the ith load point. This index showed that each customer would experience interruption several times a year.

- System average interruption duration index (SAIDI), the total interruption duration of customers in a system divided by the total number of customers in the period of study:

$$
\text { SAIDI }=\frac{\sum_{\mathrm{i}=1}^{\mathrm{n}} \mathrm{U}_{\mathrm{i}} \cdot \mathrm{N}_{\mathrm{i}}}{\sum_{\mathrm{i}=1}^{\mathrm{n}} \mathrm{N}_{\mathrm{i}}}
$$

in which $\mathrm{U}_{\mathrm{i}}$ is the interruption duration of the ith load point and $\mathrm{n}$ is the total number of load points. This index is described in terms of hours per customer in a year.

- Customer average interruption duration index (CAIDI), the total interruption duration for all customers divided by the total number of interruptions for all customers; in other words, it verifies the average interruption time per interruption:

$$
\text { CAIDI }=\frac{\sum_{\mathrm{i}=1}^{\mathrm{n}} \mathrm{U}_{\mathrm{i}} \cdot \mathrm{N}_{\mathrm{i}}}{\sum_{\mathrm{i}=1}^{\mathrm{n}} \lambda_{\mathrm{i}} \cdot \mathrm{N}_{\mathrm{i}}}
$$

- Average service availability index (ASAI), the customers' access to electricity as the percentage of hours during which the customers have access to electricity out of the total hours during the period of study:

$$
\text { ASAI }=\frac{\sum_{\mathrm{i}=1}^{\mathrm{n}} \mathrm{N}_{\mathrm{i}} \cdot \mathrm{T}-\sum_{\mathrm{i}=1}^{\mathrm{n}} \mathrm{U}_{\mathrm{i}} \cdot \mathrm{N}_{\mathrm{i}}}{\sum_{\mathrm{i}=1}^{\mathrm{n}} \mathrm{N}_{\mathrm{i}} \cdot \mathrm{T}}
$$

in which $\mathrm{T}$ is the total hours during the period of study, which in this case was $8760 \mathrm{~h}$ in a year. 
- Average service unavailability index (ASUI), the unavailability of energy, or the percentage of interruption hours out of the total hours during the period of study:

$$
\text { ASUI }=\frac{\sum_{\mathrm{i}=1}^{\mathrm{n}} \mathrm{U}_{\mathrm{i}} \cdot \mathrm{N}_{\mathrm{i}}}{\sum_{\mathrm{i}=1}^{\mathrm{n}} \mathrm{N}_{\mathrm{i}} \cdot \mathrm{T}}
$$

- Average energy not supplied (AENS), the average energy not supplied per customer in $\mathrm{kWh} /$ customer:

$$
\text { AENS }=\frac{\sum_{i=1}^{n} L_{a}(i)}{\sum_{i=1}^{n} N_{i}}
$$

in which $L_{a}(i)$ is the average load of the ith load point.

\subsection{The Proposed Reliability Evaluation Framework}

In this paper, the Monte Carlo (MC) method was used to generate the fault scenario and develop an analytical method for reliability assessment of smart grids. The Monte Carlo simulation (MCS) method is one of the most applicable system simulation methods and has been used in various studies. To calculate reliability under the proposed tariff, first, the hourly demand curve of the system (CBL) was obtained. Then, the new hourly demand curve was calculated based on the baseline price and RTP signals. The effective reliability scenarios for fault included fault in the main grid and fault in the lines. When a fault occurred in any of the DGs, the load was supplied by the grid, and load supply was not interrupted. Thus, DG faults did not affect the expected energy not supplied (EENS) and were considered as one of the fault scenarios. Thus, the total number of fault scenarios is equal to the total of the grid's fault and the lines' fault.

In this model, the following steps are taken to calculate the reliability indices:

Step 1: first, the information matrix of the IEEE 33 bus system is recalled, and the status matrix of the buses is calculated, in terms of relationships with each other and adjacency to the main grid, and recalled.

Step 2: to calculate the reliability indices, four scenarios are considered for load elasticity to examine its impact on the reliability indices. Also, the proposed tariff and the instantaneous pricing signals are used to calculate the new hourly demand curve for each scenario.

Step 3: there are various methods to calculate the initial values of the annual failure rates, the average switching time, and the average maintenance time of each element of the distribution system. In this paper, the simulation interval was one year, and all sections were the same in terms of reliability. Thus, if a fault occurred in any of the sections, it affected the total reliability of the system. The initial values of the failure rate and maintenance time were modeled using the Monte Carlo method. For this purpose, 40,000 scenarios were considered. In each scenario, the duration of the devices being healthy (T), the time required for switching (ST), and repair time (RT) were specified randomly. In the following, the results were divided by the number of scenarios $(40,000)$ and the number of days of the year to obtain the final failure rate and RT.

First, a random number with uniform distribution in the range of 0 and 1 was generated. The random number was described using a function as the duration of the element being healthy. To convert the random number to the duration of time that the element is healthy, the following function was used [57]:

$$
\mathrm{T}=-\frac{1}{\mathrm{~A}} \operatorname{Ln}(\mathrm{U})
$$

Then, another random number was generated, and the ST of the element is obtained:

$$
\mathrm{ST}=-\frac{1}{\mathrm{~B}} \operatorname{Ln}(\mathrm{U})
$$


Finally, a random number was also generated for the RT of the element:

$$
\mathrm{RT}=-\frac{1}{\mathrm{C}} \mathrm{Ln}(\mathrm{U})
$$

The parameters A, B, and C were obtained using the fault probability distribution of the elements, which was exponential. Therefore, a vector including the failure time of the elements, a vector including the ST of the elements, and a vector including the RT of the elements were obtained for one year. Figure 2 shows the scenario generation diagram for calculating the failure rate and repair time of the devices. $\mathrm{M}$ is the number of load points in the 33-bus network considering the main network, and $j$ is the number of scenarios for calculating the initial values of failure rate and equipment repair time by the Monte Carlo simulation method.

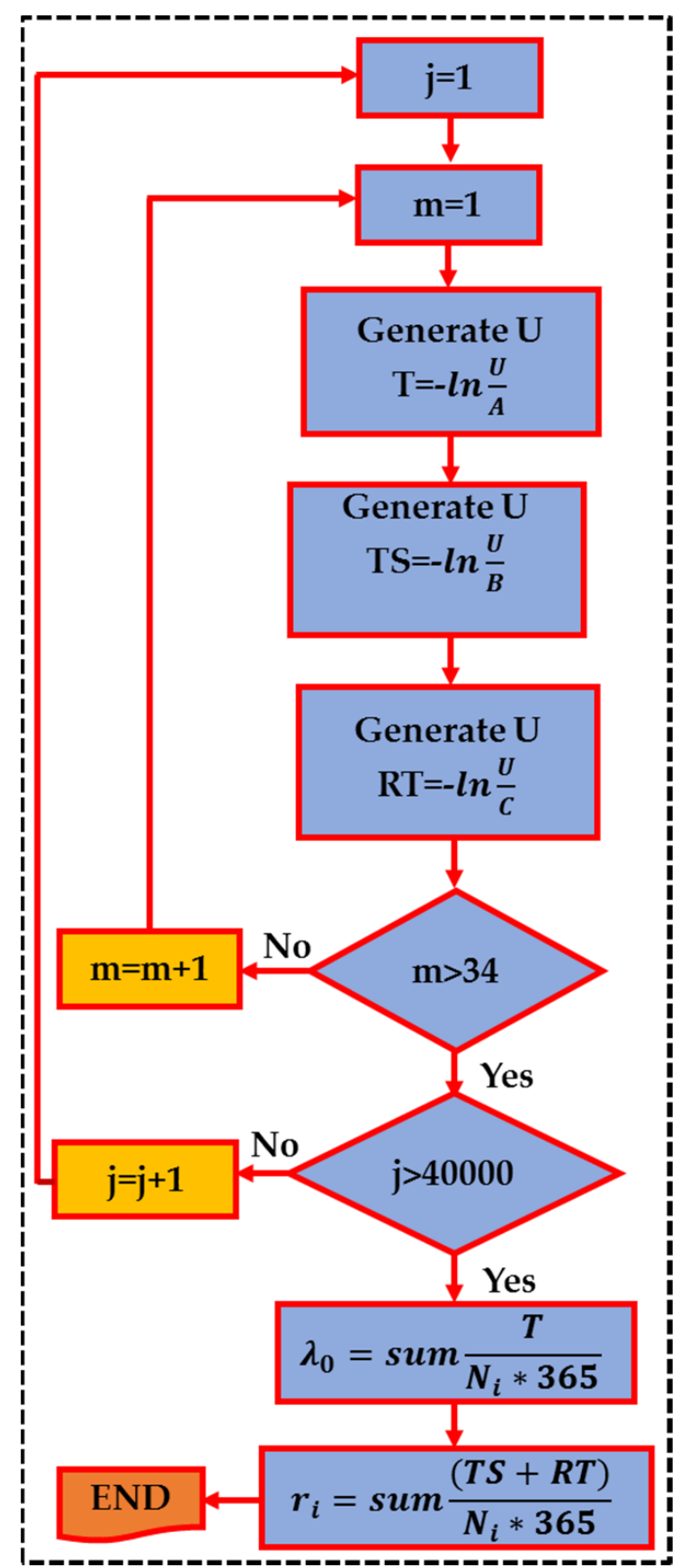

Figure 2. Generating scenario to calculate the failure rate and repair time of devices. 
Step 4: the number of load points of the distribution system, the power of the DGs, and the installation locations of the DGs are assigned.

Step 5: according to the total demand curve (PD) at time $t$, which is described in MW, the new demand for each bus $\left(D_{i}\right)$ is obtained.

Step 6: the first fault scenario is related to grid fault. For each fault scenario, the failure rate of each load and the load loss duration are obtained. When a fault occurs, the load difference of all buses with the total capacity of the up and down DGs is considered as the lost load. The lost load at the failure rate $\left(\lambda_{0}\right)$ is multiplied by the average repair time of the network $\left(\mathrm{r}_{\mathrm{i}}\right)$ and divided by the hours in a year (8760) to obtain the lost load of the first failure rate.

Step 7: when a fault occurs in the feeders, the process is a bit more complex, and the restoration of the disconnected loads should be modeled via DGs. In this step, the Busstate matrix is used, which is a 3D matrix. If a fault occurs in one feeder, this matrix specifies which bus is connected to the network and which buses are connected to each other, for example, Bus state $(\mathrm{B}, \mathrm{L},:)$ for the 33-bus system has 33 elements and shows the buses that remain connected to bus B when a fault occurs on line L. In fact, it is a vector with 33 elements that are either one or zero. If the nth element of this vector is one, it indicates that when a failure occurs on line $\mathrm{L}$, bus B remains connected to bus $\mathrm{n}$; if it is zero, it indicates that when a failure occurs on line $\mathrm{L}$, bus $\mathrm{B}$ is not connected to bus $n$. The values of the Busstate matrix are recalled first. The buses that remain connected to the network after fault are specified to calculate the indices after fault occurrence in the feeders. Then, the bus numbers of the loads that are disconnected from the grid and should be restored by the DGs are determined. Next, the bus numbers of the disconnected loads are specified using DGs.

The loads are restored based on the distance of the loads from the bus on which each DG is installed. For example, if a DG is installed on bus 10, and this bus and its adjacent buses are disconnected from the grid, the DG restores the load of its bus and the adjacent buses until its capacity is completed. In this process, the loads closer to the DG are of higher priority. For this purpose, a matrix is generated in which the buses close to each bus are sorted based on their adjacency to the bus of interest. This matrix is a 2D matrix (Bus Order $_{\text {) }}$ in which each row is equivalent to a bus.

Finally, the state of each load is specified by the $\operatorname{Load}_{\text {state }}(\mathrm{k}, \mathrm{L})$ vector, which represents the load restoration percentage at bus $\mathrm{L}$ and scenario $\mathrm{k}$. If the state is one, the total load of bus L is restored, and if it is zero, the total load of bus L is lost. After obtaining the restoration percentage of each load, the lost load (fault in the main grid) can be calculated for the fault scenarios of the grid lines.

Step 8: for all fault scenarios, the total failure rate of each load $\left(\lambda_{\mathrm{i}}\right)$ is calculated as the total of all failures, and the interruption duration $\left(\mathrm{U}_{\mathrm{i}}\right)$ is calculated as the total of all interruptions.

Step 9: the reliability indices are calculated based on the obtained information.

The general algorithm of the method presented for calculating the reliability indices is shown in Figure 3. 


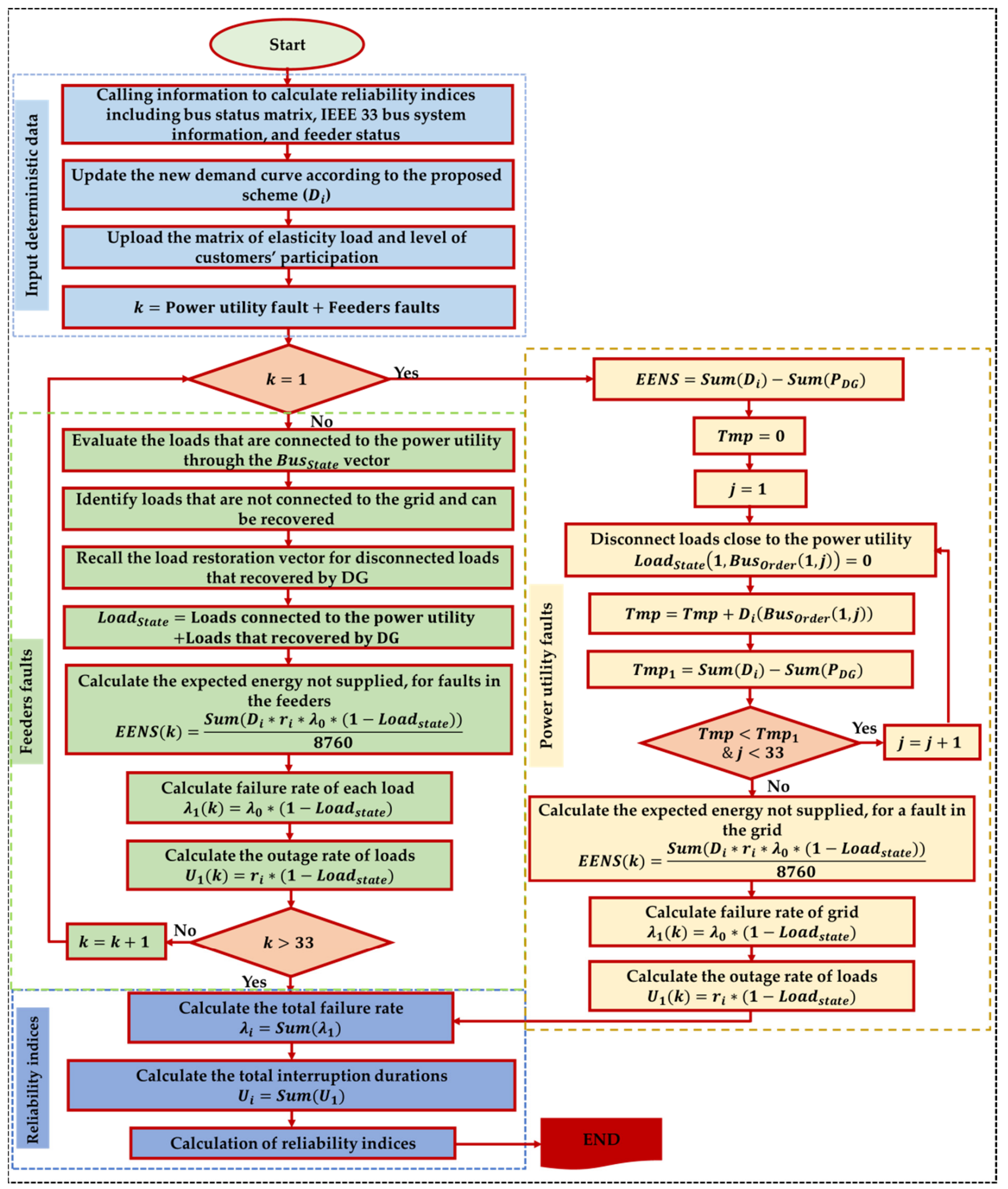

Figure 3. The algorithm proposed for evaluating reliability in smart distribution networks.

\section{Numerical Study}

In this section, the short-term effect of employing the proposed tariff on the operation decision, load level, DSO profit, and operator costs is studied. Its long-term effect on 
reliability indices of a sample distribution system [57] is also studied considering the 1-year load profile.

\subsection{Short-Term}

In this section, the effect of employing the proposed instantaneous pricing tariff on operation decisions was studied. Figure 4 shows a schematic of the studied DS. The maximum power generation capacities of (DG1, DG2) and (DG3, DG4) were 5 MW and $4 \mathrm{MW}$, respectively.

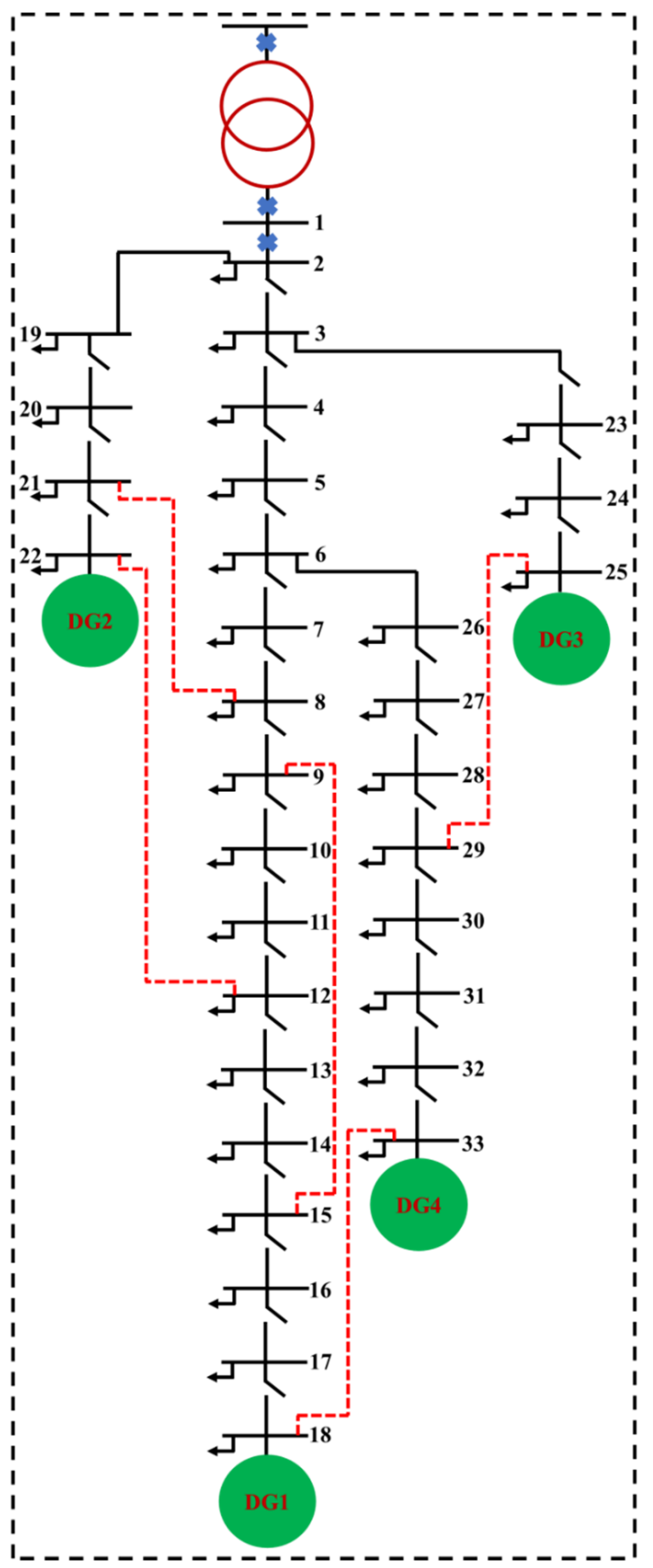

Figure 4. Single-line diagram of IEEE 33-bus distribution system. 
The simulations were performed using GAMS and MATLAB. The problem was solved as a mixed integer linear programming (MILP) model in GAMS 24.1. This type of programming in GAMS was specified using MIP, and the solver of this problem was CPLEX [58].

MATLAB was used to calculate the effect of pricing method on the demand curve and the customers' payment. Finally, the final demand curve obtained from MATLAB was used to solve the operation problem and calculate the profit. In this section, three studies were conducted. In the first study, which aimed to analyze the effect of DSO signals, the time-variant electricity price was integrated with the DS performance, investigating the risk to customers' payment resulting from price fluctuations by changing the DR percentage. The purpose of the second study was to analyze the effect of customers' participation in the tariff; therefore, in the scenarios defined for the second study, the participation level varied, but the sensitivity of the customers participating in the tariff was fixed regarding the price changes. In the third study, it was assumed that there was a specific level of customer participation and that the customers' sensitivity to the prices changed. An increase in $\varepsilon$ indicated that the customers' sensitivity to price changes increased. Short-term studies were intended here for $24 \mathrm{~h}$ a day on a winter day, which can be generalized to a season by averaging the price signals.

\subsubsection{The First Study}

This study investigated the effect of DR percentage on the customers' energy consumption payment risk. To this end, first, the baseline price signals TOU and RTP were given. It should be mentioned that since RTP is associated with the real-time price of the electricity market, it was uncertain. Three different scenarios were considered for pricing to cover the uncertainty (Figure 5). Then, the demand curve was calculated for different price scenarios.

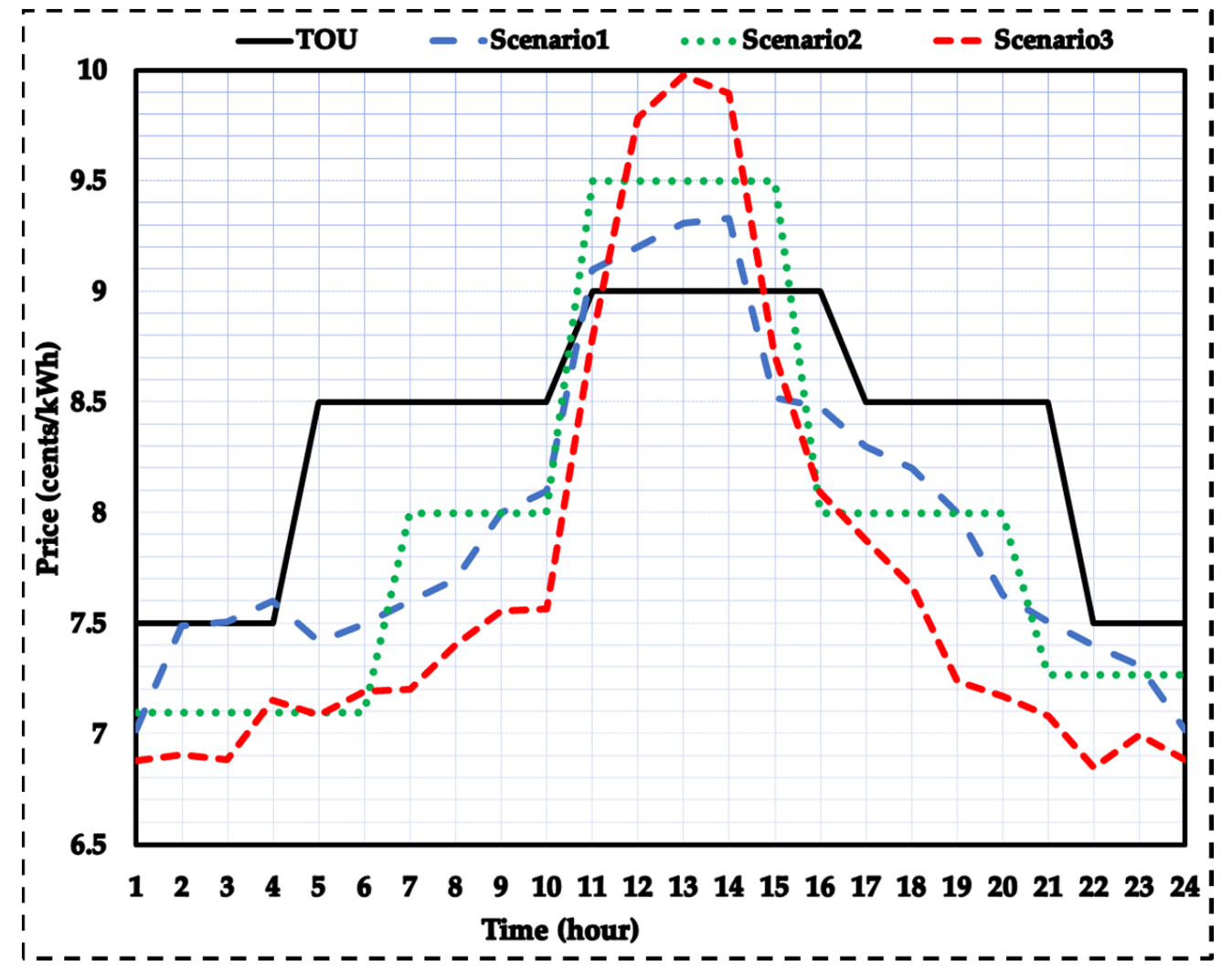

Figure 5. TOU and RTP curves for different scenarios.

The percentage of the load that was reprogrammable was defined using $\zeta$, and it was equal to 0.015 . $E_{c}$ is a diagonal matrix that represents load elasticity for $24 \mathrm{~h}$, and it was 
considered to be 0.4 . Figure 6 shows the demand curve for different pricing scenarios based on the proposed tariff. As can be seen, in all scenarios, the consumption decreased at all peak times and increased at nonpeak times under the proposed tariff.

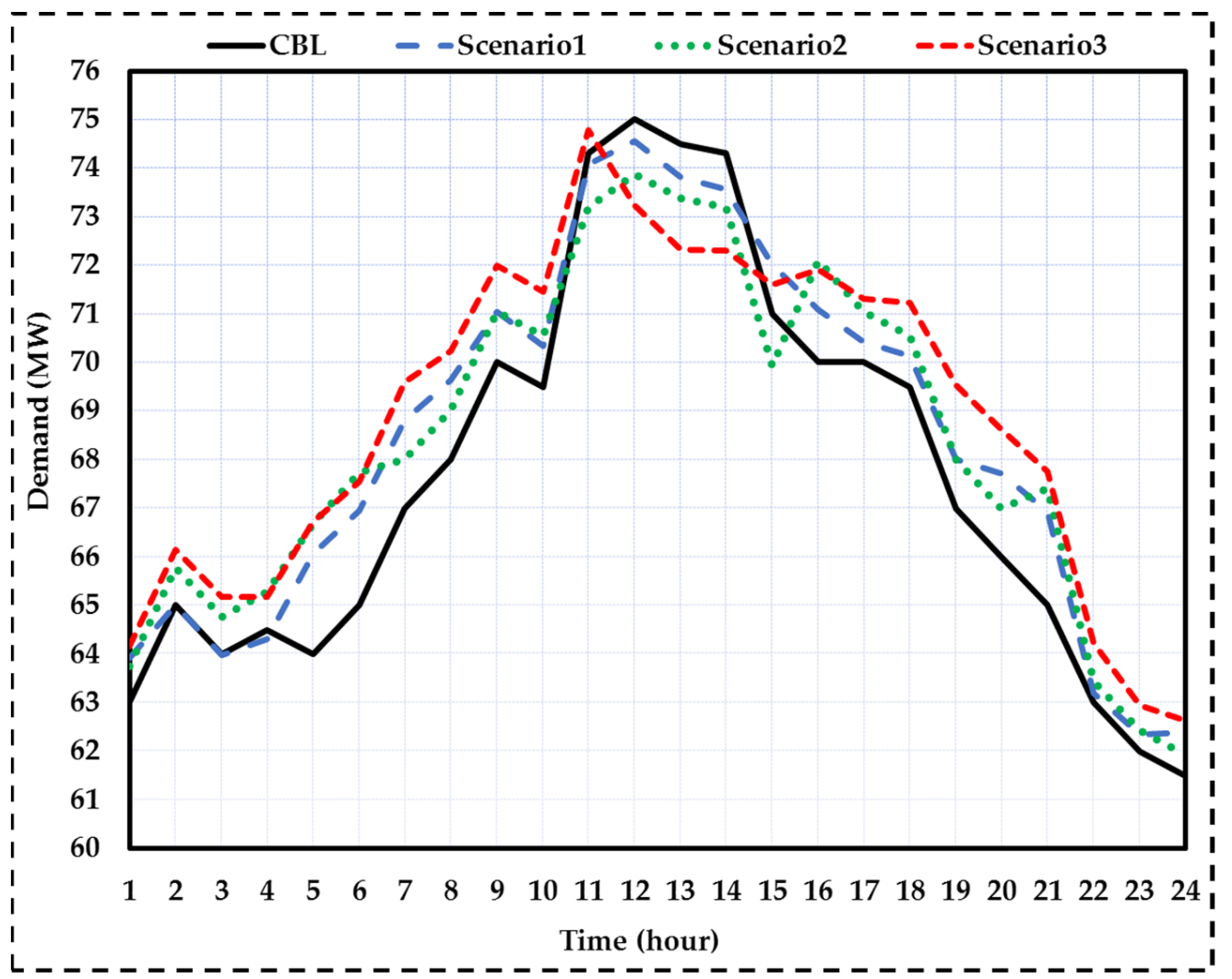

Figure 6. Effect of the proposed pricing tariff on the demand curve for different scenarios.

Table 2 shows the minimum and maximum payments of customers based on normal pricing and the proposed pricing tariff. As can be seen, the proposed scheme reduced the customers' payment changes significantly. The payment risk was equal to the difference of the maximum payment and the average payment. The difference between the customers' payment in the best and worst scenarios under the normal one-sectional RTP was 1140.8 USD, while it was 516.54 USD under the proposed scheme. In other words, the proposed scheme reduced the payment risk by $54 \%$, because unlike the normal RTP scheme, which calculates the total consumption of the customers with the unstable price of the electricity market (which is uncertain), the proposed scheme calculates the different between the TOU and the consumption curve with the electricity market price.

Table 2. The customers' payment in the best and worst scenarios (USD).

\begin{tabular}{ccc}
\hline & Proposed Scheme (USD) & Present RTP (USD) \\
\hline Best scenario payment & $1.3774 \times 10^{5}$ & $1.3129 \times 10^{5}$ \\
Worst scenario payment & $1369 \times 10^{5}$ & $1.279 \times 10^{5}$ \\
Payment exposure risk & 516.54 & 1140.8 \\
\hline
\end{tabular}

In the next section, the effect of load participation in DR on payment risk was studied. To this end, five different values were considered for load participation in the DR, which was defined as the DR vector. These values varied from 0 to $80 \%$ with a step of $20 \%$. Finally, the payment risk and expected payment were obtained and stored for each value.

Figure 7 shows the payment risk vs. DR percentage. As customer participation in the proposed tariff increased, the payment risk also increased, while in the existing RTP 
scheme, the payment risk decreased as the responsive load increased. This was because under the proposed scheme, if a customer does not change their normal consumption pattern (CBL), no price change is applied to any part of the customer's consumption. According to the term $\left(\mathrm{PD}_{\mathrm{t}}-\mathrm{CBL}_{\mathrm{t}}\right)$ in calculating customer invoices, the further away a subscribers' consumption was from the $\mathrm{CBL}$, the difference of the consumers' payment with the baseline payment was higher. Also, Figure 7 shows that customer risk under the proposed scheme was lower than the risk under the existing RTP for all responsive loads. From Figure 8, it can be found that the expected consumption of the customers was almost the same. The changes in the responsive loads changed the customers' payment for different scenarios, but the expected payment, which is the average of these payments, remained almost unchanged.

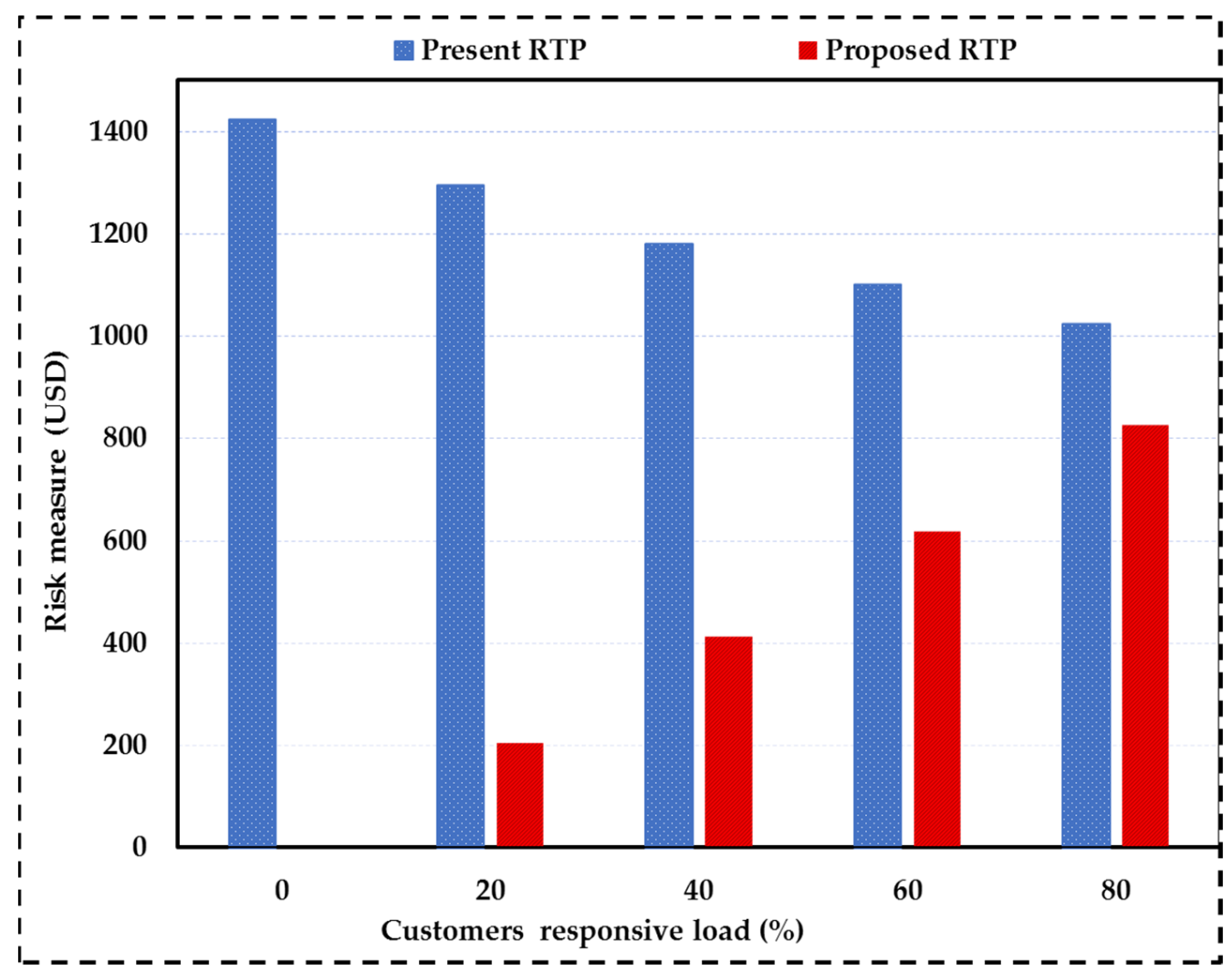

Figure 7. Effect of load participation in DR on the payment risk.

Table 3 shows the income details $\left(\mathrm{BL}_{\mathrm{t}}^{\text {Total }}\right)$, load interruption cost $\left(\mathrm{C}_{\mathrm{t}}^{\mathrm{IL}}\right)$, operation cost of the DGs $\left(C_{t}^{D G}\right)$, cost of buying electricity from the grid $\left(C_{t}^{\text {Grid }}\right)$, and DSO profit $(P)$. The maximum load interruption at each hour and each bus was considered to be equal to $5 \%$ of the load. The results showed that according to the proposed tariff, the DSO profit was higher than normal, because in this case, the DSO income increased.

Table 3. DSO income and operation costs for two pricing schemes (USD).

\begin{tabular}{|c|c|c|c|c|c|}
\hline Pricing Scheme & $\begin{array}{l}\text { DSO Income } \\
\left(\mathrm{BL}_{\mathrm{t}}^{\text {Total }}\right)\end{array}$ & $\begin{array}{l}\text { Purchase from } \\
\text { Grid }\left(C_{t}^{\text {Grid }}\right)\end{array}$ & IL Purchase $\left(C_{t}^{I L}\right)$ & $\begin{array}{l}\text { DG Generation } \\
\left(C_{t}^{D G}\right)\end{array}$ & DSO Profit (P) \\
\hline Existing present RTP scheme & 131,287 & 96,788 & 160.566 & $14,320.00$ & $20,018.2$ \\
\hline The proposed RTP scheme & 137,023 & 96,788 & 160.566 & $14,320.00$ & 25,754 \\
\hline
\end{tabular}




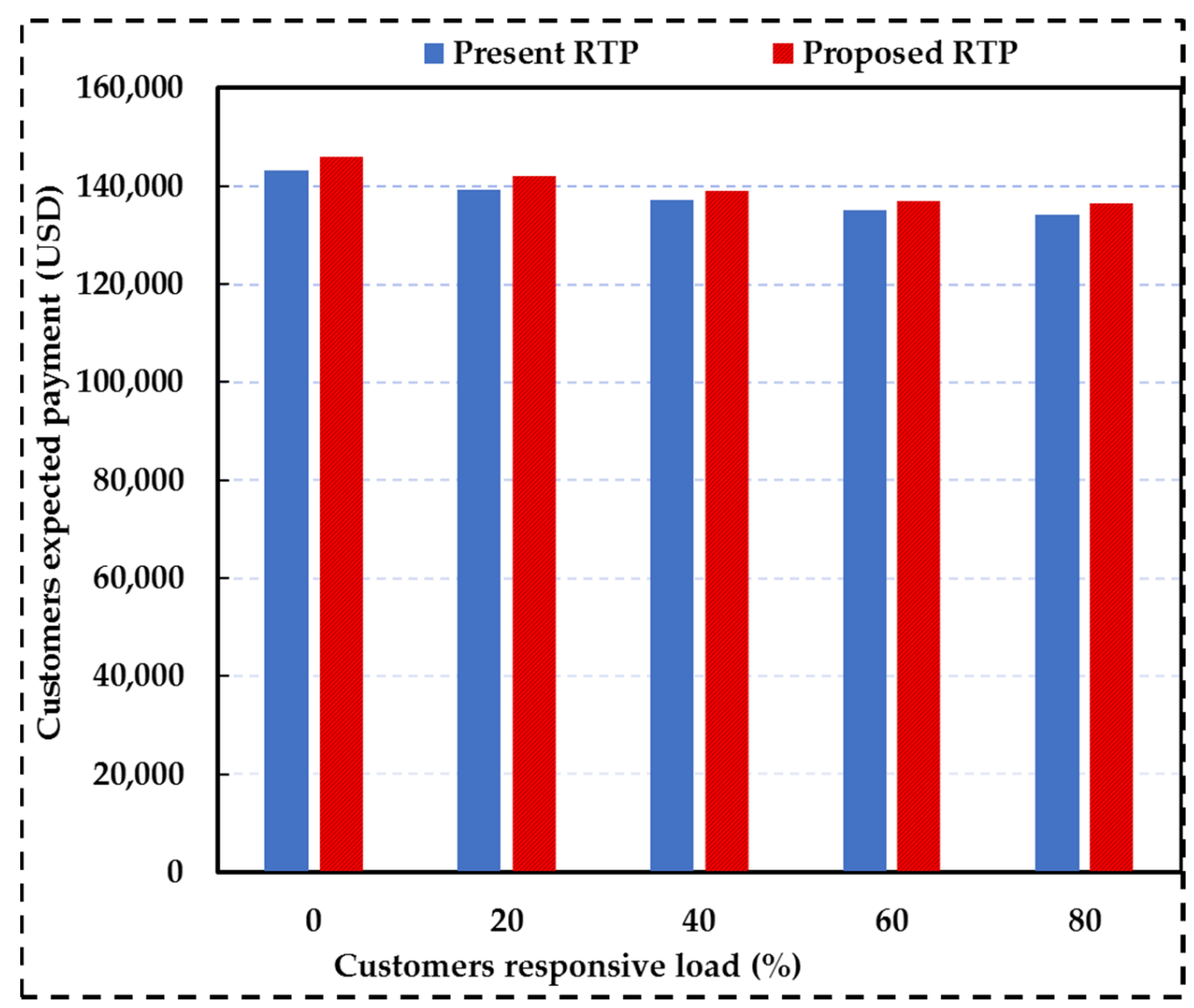

Figure 8. Effect of load participation in DR on the average customer payment.

\subsubsection{The Second Study}

In this study, the effect of customers' participation on operation decisions, customer invoices, DSO profit, and load level was investigated. In this section, the baseline price and RTP price (Scenario 1) were considered as the inputs. Table 4 shows the DSO profit vs. costs and income. The represented profit is called the baseline profit, because it was calculated assuming that customer participation in the proposed program was zero $(\mathrm{DR}=0)$ and the prices did not change $\left(\mathrm{E}_{\mathrm{c}}=0\right)$. In other words, this profit was calculated assuming that the load profile was equal to CBL and that customers did not change their consumption in response to prices.

Table 4. Costs and incomes of the DS in basic case.

\begin{tabular}{|c|c|c|c|c|c|c|}
\hline Pricing Scheme & Enrollment Level & $\begin{array}{c}\left(\mathrm{BL}_{\mathrm{t}}^{\text {Total }}\right) \\
\text { (USD) }\end{array}$ & $\begin{array}{l}\left(C_{t}^{\text {Grid }}\right) \\
\text { (USD) }\end{array}$ & $\begin{array}{c}\left(\mathrm{C}_{\mathrm{t}}^{\mathrm{IL}}\right) \\
(\mathrm{USD})\end{array}$ & $\begin{array}{r}\left(C_{t}^{D G}\right) \\
(U S D)\end{array}$ & $\begin{array}{c}\text { (P) } \\
\text { (USD) }\end{array}$ \\
\hline Existing RTP scheme & 0 & 135,729 & $95,391.42$ & 383.057 & 14,320 & $25,634.52$ \\
\hline Proposed RTP scheme & 0 & 129,993 & $94,391.42$ & 383.057 & 14,320 & $19,898.76$ \\
\hline
\end{tabular}

Figure 9 shows the improvement in the operation profit between the existing and proposed tariffs regarding the baseline case. The red curve shows the improvement of the total operation profit using the proposed tariff, and the blue curve shows the profit percentage for the normal RTP tariff. The proposed model was more effective than the normal tariff and increased the profit by eliminating the possibility of changing the market price as a result of increasing the participation level of the customers in the pricing tariff. 


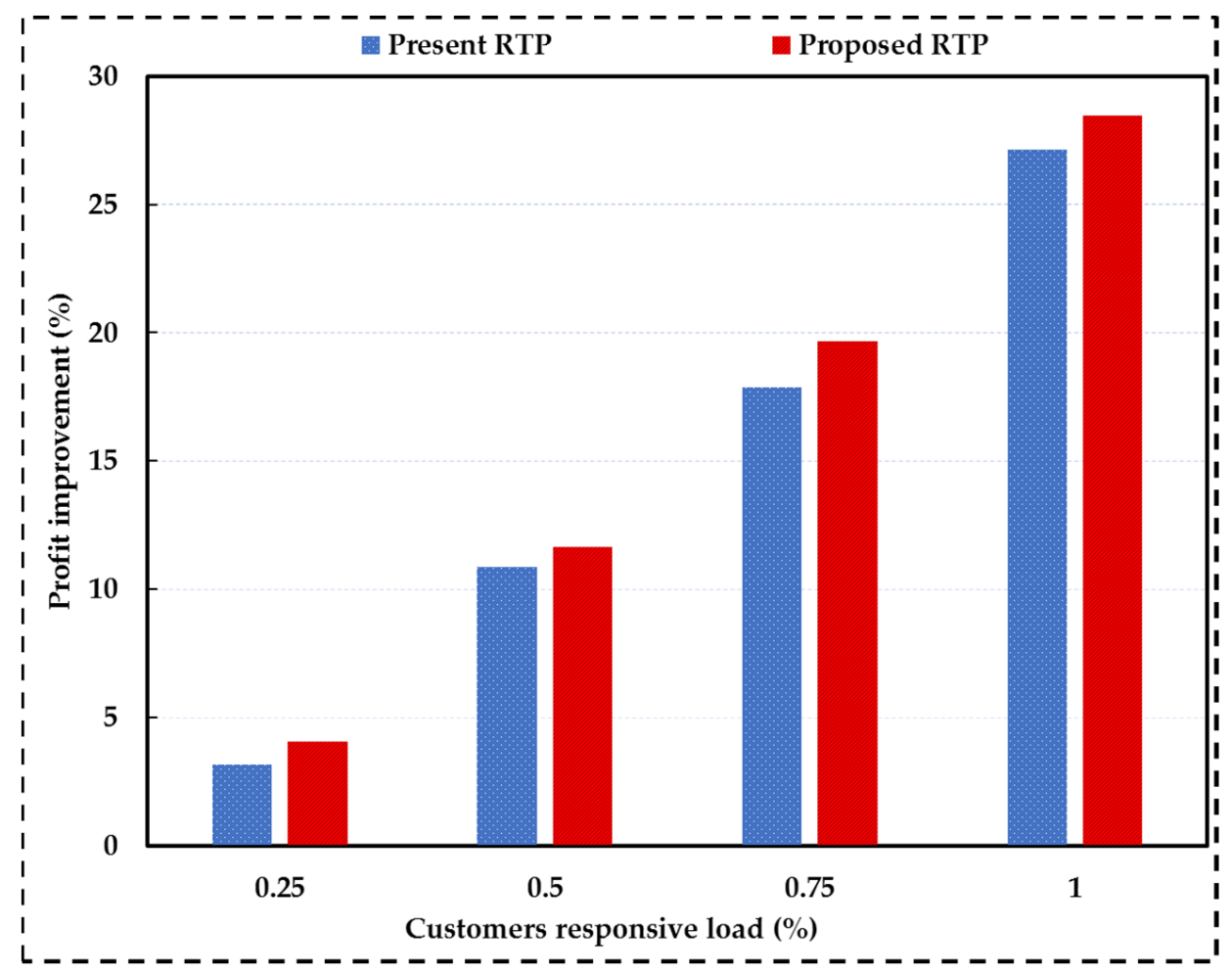

Figure 9. Improvement of the operator profit compared to the baseline case and changes in the customers' participation level in the DR.

Table 5 shows the changes in different components of the profit, income, and DSO profit based on changes in the customers' participation in the proposed program. The DGs' cost was fixed. As can be seen, as the participation level increased, the cost of buying electricity from the gird decreased, and the contract with interruptible loads also decreased because the consumption decreased at peak times.

Table 5. Changes in different components of profit, cost, and income based on participation level in the DR.

\begin{tabular}{|c|c|c|c|c|c|c|}
\hline DR & $\begin{array}{c}\left(\mathrm{BL}_{\mathrm{t}}^{\text {Total }}\right) \\
\text { (USD) }\end{array}$ & $\begin{array}{l}\left(C_{t}^{\text {Grid }}\right) \\
\text { (USD) }\end{array}$ & $\begin{array}{c}\left(\mathrm{C}_{\mathrm{t}}^{\mathrm{IL}}\right) \\
(\mathrm{USD})\end{array}$ & $\begin{array}{l}\left(C_{t}^{D G}\right) \\
(U S D)\end{array}$ & $\begin{array}{c}\text { (P) } \\
\text { (USD) }\end{array}$ & Improvement $(\%)$ \\
\hline $25 \%$ & $136,160.2$ & $94,858.56$ & 305.564 & 14,320 & $26,676.1$ & 4.0631773 \\
\hline $50 \%$ & $136,591.4$ & $93,425.6$ & 228.285 & 14,320 & $28,617.56$ & 11.6367851 \\
\hline $75 \%$ & $137,022.7$ & $92,121.18$ & 160.566 & 14,320 & $30,420.92$ & 18.6716701 \\
\hline $100 \%$ & $137,453.9$ & $90,338.57$ & 119.006 & 14,320 & $32,676.31$ & 27.4699234 \\
\hline
\end{tabular}

\subsubsection{The Third Study}

In this study, the effects of customers' sensitivity to prices on operation decisions, customers' invoices, DSO profit, and load level were investigated. In this study, it was assumed that $75 \%$ of customers had registered in the proposed tariff. Figure 10 shows the profit increase under the proposed tariff compared to the basic case. The red curve shows the improvement of the operator's total profit when employing the proposed tariff. This figure shows that as the customers' sensitivity to prices under both tariffs increased, the operation profit increased. The proposed pricing tariff was more effective and increased the profit further. 


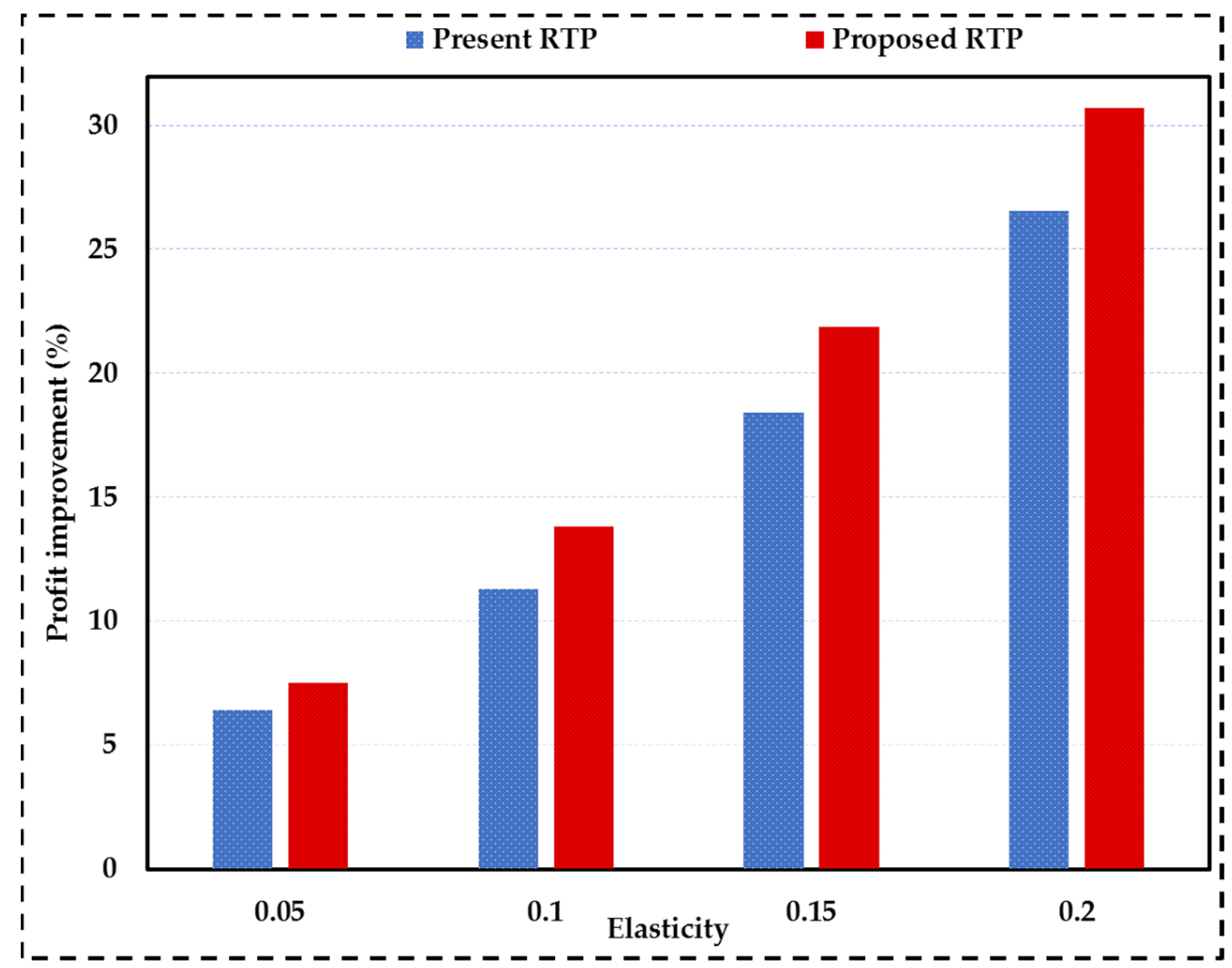

Figure 10. Improvement in operator profit compared to the basic case and changes in load elasticity.

Table 6 shows changes in different elements of profit, income, and cost for different elasticity scenarios. Although increasing the elasticity increased the DSO income, it decreased the operation costs significantly.

Table 6. Changes in different elements of profit, cost, and income for different elasticity scenarios.

\begin{tabular}{ccccccc}
\hline $\mathbf{E}$ & $\begin{array}{c}\left.\mathbf{( B L}_{\mathbf{t}}^{\text {Total}}\right) \\
(\mathbf{U S D})\end{array}$ & $\begin{array}{c}\mathbf{( C}_{\mathbf{t}}^{\text {Grid }} \\
(\mathbf{U S D})\end{array}$ & $\begin{array}{c}\left.\mathbf{( C}_{\mathbf{t}}^{\mathrm{IL}}\right) \\
(\mathbf{U S D})\end{array}$ & $\begin{array}{c}\mathbf{( C}_{\mathbf{t}}^{\mathbf{D G})} \\
(\mathbf{U S D})\end{array}$ & $\begin{array}{c}(\mathbf{P}) \\
(\mathbf{U S D})\end{array}$ & Improvement (\%) \\
\hline 0.05 & $136,591.4$ & $94,375.1$ & 344.203 & 14,320 & $27,552.2$ & 7.481 \\
0.1 & $137,453.9$ & $93,658.6$ & 305.564 & 14,320 & $29,169.8$ & 13.791 \\
0.15 & $138,316.3$ & $92,492.1$ & 266.925 & 14,320 & $31,237.3$ & 21.856 \\
0.2 & $139,178.8$ & $91,125.6$ & 228.285 & 14,320 & $33,504.9$ & 30.702 \\
\hline
\end{tabular}

\subsubsection{Time-Varying Electricity Rates}

The real-time pricing method proposed in this paper was compared with time-of-use (TOU) pricing methods and critical peak pricing (CPP) [23], and the comparison results in a sample day are given in Table 7 .

Table 7. Changes in different elements of profit, cost, and income for different elasticity scenarios (USD).

\begin{tabular}{cccccc}
\hline Electricity Rate & $\left.\mathbf{( B L}_{\mathbf{t}}^{\text {Total }}\right)$ & $\left.\mathbf{( C}_{\mathbf{t}}^{\text {Grid }}\right)$ & $\left.\mathbf{( C}_{\mathbf{t}}^{\mathbf{I L}}\right)$ & $\left.\mathbf{( C}_{\mathbf{t}}^{\text {DG }}\right)$ & $\mathbf{( P )}$ DSO Profit \\
\hline TOU & 133,160 & $95,383.1$ & 539.9 & 14,320 & 22,917 \\
CPP & 127,822 & $107,557.5$ & 541.5 & 14,320 & 5403 \\
RTP & 137,023 & 96,788 & 160.566 & 14,320 & 25,754 \\
\hline
\end{tabular}

In TOU, different time intervals are determined in which the prices are fixed; however, prices vary from one interval to another. These intervals might be different hours of a day. In CPP, the prices are fixed in different intervals, but they increase significantly for the 
peak range in which the demand is high, and the customers usually receive the new price information one day ahead. In the RTP method, the electricity price is variable in all hours and reflects the market price. The results given in Table 7 show that TOU and RTP increased the DSO profit significantly, while CPP reduced the DSO profit. Therefore, considering the increase in DSO profit and decrease in operation costs using RTP compared to the two other methods, RTP is the most appropriate method for the proposed pricing tariff.

\subsubsection{Verification of the Results' Accuracy}

As mentioned before, to solve the operation problem, the MILP model was solved using GAMS and CPLEX 24.1.3. The tests were carried out using an Intel core i3 3217u $2.1 \mathrm{GHz}$ processor with $4 \mathrm{~GB}$ RAM. Because of the large number of constraints, the binary variables and the parameters, convergence, and accuracy of the model were investigated. Tables 8 and 9 show the "best solution", "absolute gap", and "computation time" of the results with sufficient accuracy for different cases. As can be seen, the results were in good agreement and demonstrated convergence of the algorithm. In these calculations, the linearization method was used to solve the power flow equations. Comparison of the results of the linear and nonlinear equations showed that the results were very close to each other, but the computation time for linear methods was much shorter than that for nonlinear methods.

Table 8. The output of CPLEX 24.1.3 for each study case with linear equations such as AC power flow constraints.

\begin{tabular}{ccccc}
\hline Case & Model & Best Solution (USD) & Absolute Gap & Computation Time (Min.) \\
\hline $\mathrm{DR}=0, \mathrm{E}=0.04$ & MILP & $19,898.76$ & $0 \%$ & 0.25 \\
$\mathrm{DR}=0.25, \mathrm{E}=0.04$ & MILP & $26,676.1 .6$ & $0 \%$ & 5 \\
$\mathrm{DR}=0.5, \mathrm{E}=0.04$ & MILP & $28,617.56$ & $0 \%$ & 5.09 \\
$\mathrm{DR}=0.75, \mathrm{E}=0.04$ & MILP & $30,420.92$ & $0 \%$ & 5.11 \\
\hline
\end{tabular}

Table 9. The output of CPLEX 24.1.3 for each study case with nonlinear equations such as AC power flow constraints.

\begin{tabular}{ccccc}
\hline Case & Model & Best Solution (USD) & Absolute Gap & Computation Time (Min.) \\
\hline $\mathrm{DR}=0, \mathrm{E}=0.04$ & MILP & $19,899.8$ & $0 \%$ & 8 \\
$\mathrm{DR}=0.25, \mathrm{E}=0.04$ & MILP & $26,677.2$ & $0 \%$ & 26.4 \\
$\mathrm{DR}=0.5, \mathrm{E}=0.04$ & MILP & $28,618.6$ & $0 \%$ & 26.67 \\
$\mathrm{DR}=0.75, \mathrm{E}=0.04$ & MILP & 30,423 & $0 \%$ & 26.78 \\
\hline
\end{tabular}

\subsection{Long-Term}

In this section, the long-term effect of instantaneous pricing on the reliability indices of the system was investigated. It was assumed that the customers' behavior was optimal and that customers transferred load at peak times to other times. The response of customers to prices was modeled using the load elasticity concept. The load profile was examined first to calculate the DS reliability using the proposed method. To this end, two different cases were considered for the load profile. In the first case, the DR changed for each load curve, and in the second case, the elasticity changed. The conventional methods for calculating the reliability indices could not demonstrate the changes resulting from changes in the load profile, because these methods used the average load instead of the load profile, and the average load was fixed in all load profiles. The important point is that by implementing the proposed instantaneous pricing program, the load profile became more uniform, and the load peak decreased.

\subsubsection{First Case: Calculating Reliability Indices vs. DR Changes}

In this section, four scenarios were considered for determining customer participation. The purpose of determining these scenarios was to specify the effect of the number of participants on different reliability indices. For this purpose, 40,000 scenarios were consid- 
ered for simulating the failure rate and repair time using the Monte Carlo method. The reliability indices of the baseline case $\left(\mathrm{E}_{\mathrm{c}}=0, \mathrm{DR}=0\right)$ are given in Table 10.

Table 10. Reliability indices in the basic case.

\begin{tabular}{cc}
\hline Reliability Indices & Value \\
\hline SAIFI (interrupt/customer/year) & 3.5404 \\
SAIDI (hours/customer/year) & 14.6565 \\
CAIDI (hours/interruption) & 4.1399 \\
ASAI & 0.9984 \\
ASUI & 0.00165 \\
ENS(MWh/year) & 23.6110 \\
AENS (KWh/customer/year) & 14.5468 \\
\hline
\end{tabular}

The results of the proposed method for calculating the reliability indices in baseline are compared with the results obtained using the two other references in Table 11. The numerical results showed that the reliability indices of the proposed framework were reduced compared to the those of the other two methods, as the expected energy-notsupplied index was reduced under the proposed method, and customer satisfaction was increased.

Table 11. Comparing the reliability indices of the proposed method with other studies.

\begin{tabular}{ccccc}
\hline Solution Approaches & SAIFI & SAIDI & CAIDI & ASAI \\
\hline Model presented in [55] & 21.5210 & 40.3415 & 1.875 & 0.9985 \\
Model presented in [59] & 5.35187 & 927.25 & 173.25 & 0.9987 \\
Proposed model & 3.5404 & 14.656 & 4.1399 & 0.9984 \\
\hline
\end{tabular}

As customer participation increased at a fixed elasticity $\left(E_{c}=0.45\right)$, the reliability indices of the distribution network decreased. Comparison with the results (shown in Table 12) showed that when customer participation in the proposed tariff increased, the reliability indices that rely on the load level decrease because the consumption load curve became smooth; indeed, some indices directly relied on the failure rate of the devices, and their changes in response to changes in load consumption were negligible. Figure 11 shows changes in reliability indices compared to the basic case, indicating improvement in reliability as customer participation increased.

Table 12. Changes in reliability indices based on DR for $E_{c}=0.45$.

\begin{tabular}{cccccccc}
\hline DR & SAIFI & SAIDI & CAIDI & ASAI & ASUI & ENS & AENS \\
\hline 0 & 3.54038 & 14.6565 & 4.1399 & 0.99835 & 0.001649 & 23.6109 & 14.5468 \\
0.25 & 3.51957 & 14.5818 & 4.1432 & 0.99835 & 0.001649 & 22.9618 & 14.3912 \\
0.50 & 3.50378 & 14.5229 & 4.14501 & 0.99835 & 0.001649 & 22.4406 & 14.3117 \\
0.75 & 3.48817 & 14.4669 & 4.14742 & 0.99835 & 0.001649 & 21.9928 & 14.1924 \\
1 & 3.48297 & 14.4482 & 4.14823 & 0.99835 & 0.001649 & 21.7581 & 14.1527 \\
\hline
\end{tabular}

\subsubsection{Second Case: Calculating Reliability Indices as Load Elasticity Changes}

In this section, four scenarios were considered for load elasticity. The purpose of determining these scenarios was to determine the effect of customers' sensitivity to price changes on various reliability indices. In this case, the DR for different elasticities was considered to be $50 \%$. As shown in Table 13, increasing load elasticity improved the reliability of some indices and did not affect other indices, because increasing elasticity decreased the load peak and the pressure on the system, improving reliability. However, some reliability indices, such as ASAI and ASUI, depend on the failure rate of the devices; thus, the impact of increasing elasticity on these indices was negligible. 
Table 13. Changes of reliability indices on load elasticity for $\mathrm{DR}=0.5$.

\begin{tabular}{cccccccc}
\hline Self-Elasticity & SAIFI & SAIDI & CAIDI & ASAI & ASUI & ENS & AENS \\
\hline 0 & 3.5404 & 14.6565 & 4.1399 & 0.9984 & 0.00165 & 23.6110 & 14.5468 \\
0.15 & 3.5300 & 14.6191 & 4.1416 & 0.9984 & 0.00165 & 23.2183 & 14.4686 \\
0.30 & 3.5103 & 14.5469 & 4.1441 & 0.9984 & 0.00165 & 22.7673 & 14.3519 \\
0.45 & 3.5038 & 14.5229 & 4.1450 & 0.9984 & 0.00165 & 22.4405 & 14.3116 \\
0.60 & 3.4882 & 14.4669 & 4.1474 & 0.9984 & 0.00165 & 21.9928 & 14.1923 \\
\hline
\end{tabular}

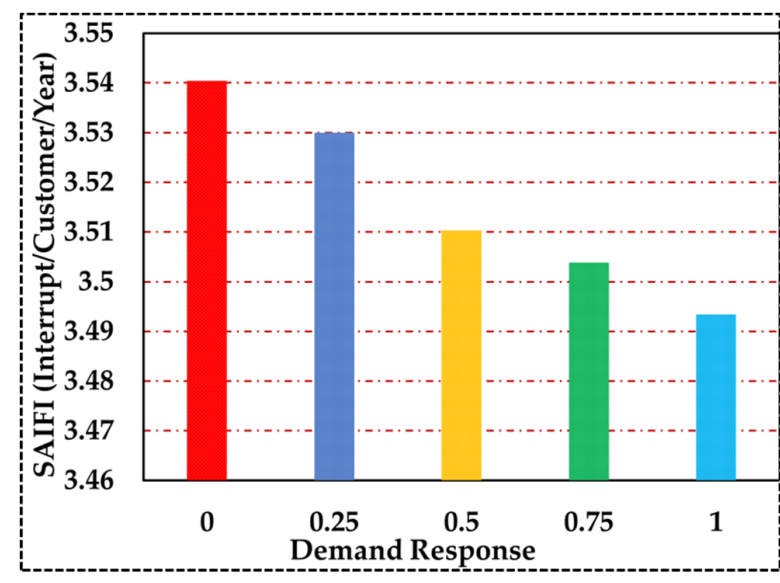

(a)

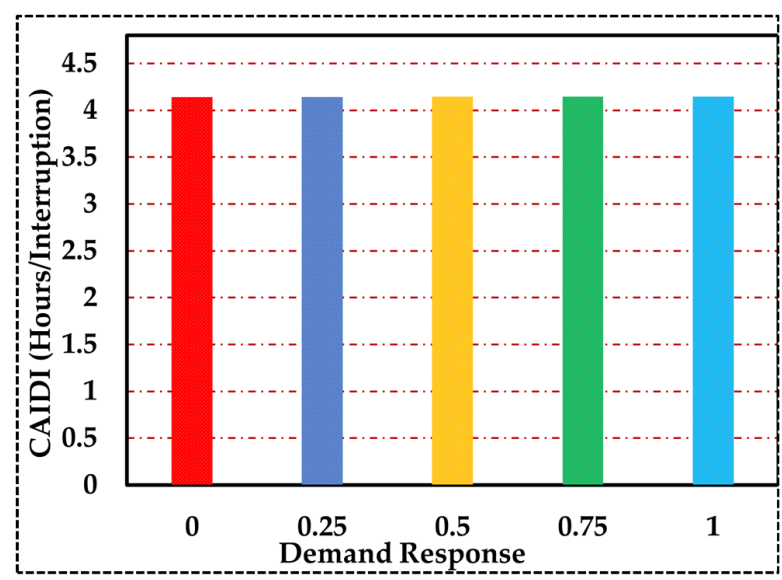

(c)

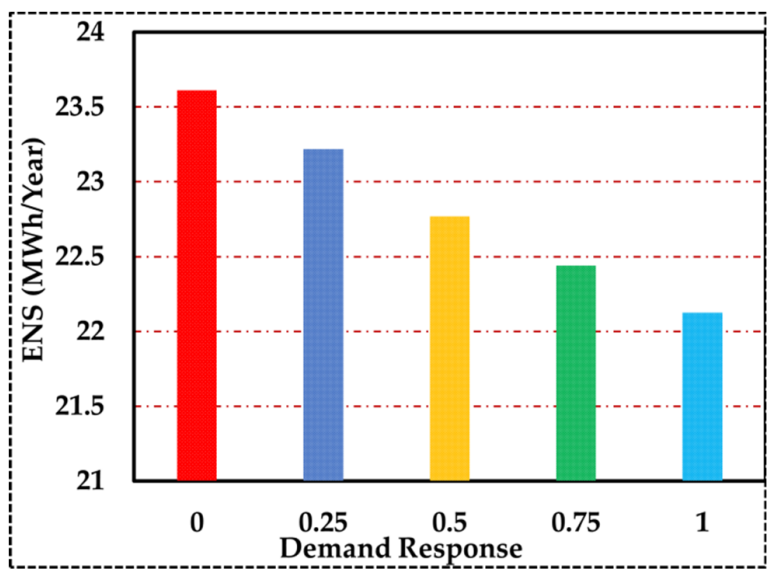

(e)

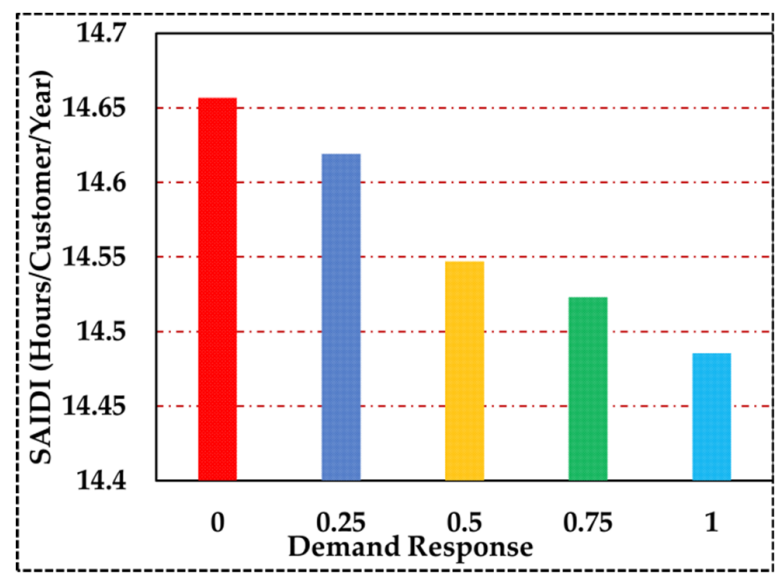

(b)

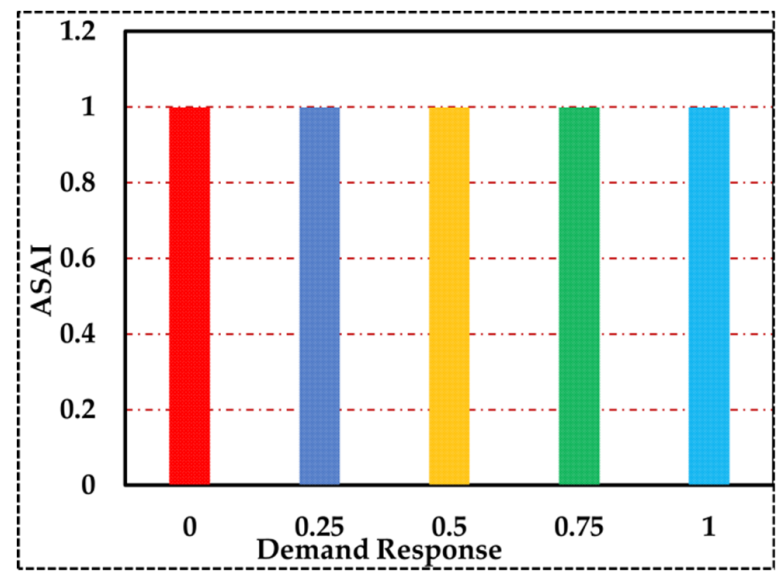

(d)

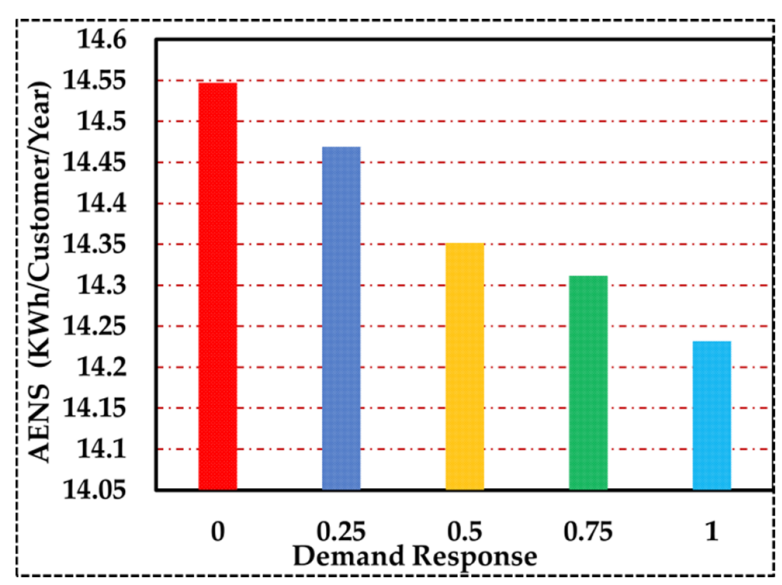

(f)

Figure 11. Changes in reliability indices based on DR for $\mathrm{E}_{\mathrm{c}}=0.3$. (a) SAIFI; (b) SAIDI; (c) CAIDI; (d) ASAI; (e) ENS; (f) AENS. 
Figure 12 shows changes in reliability indices for different elasticities for DR of 0.75 . The diagrams show that indices such as SAIFI, SAIDI, and ENS improved up to the point that the load curve did not fluctuate.

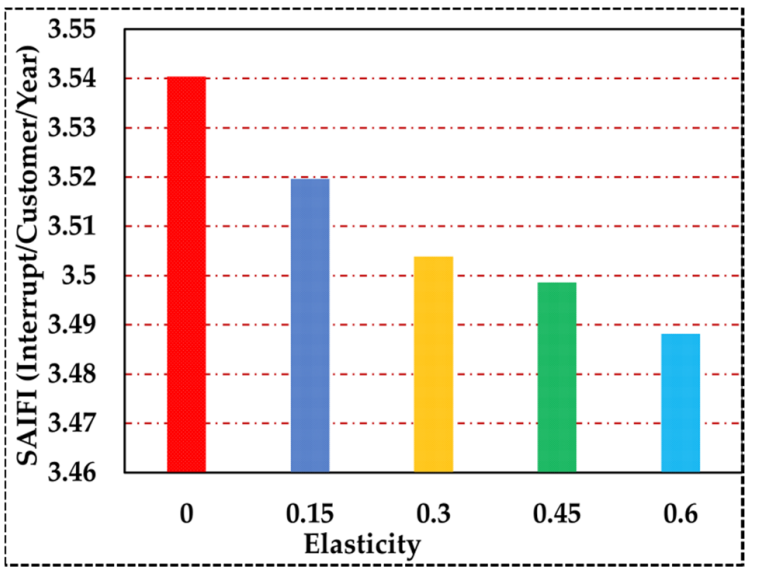

(a)

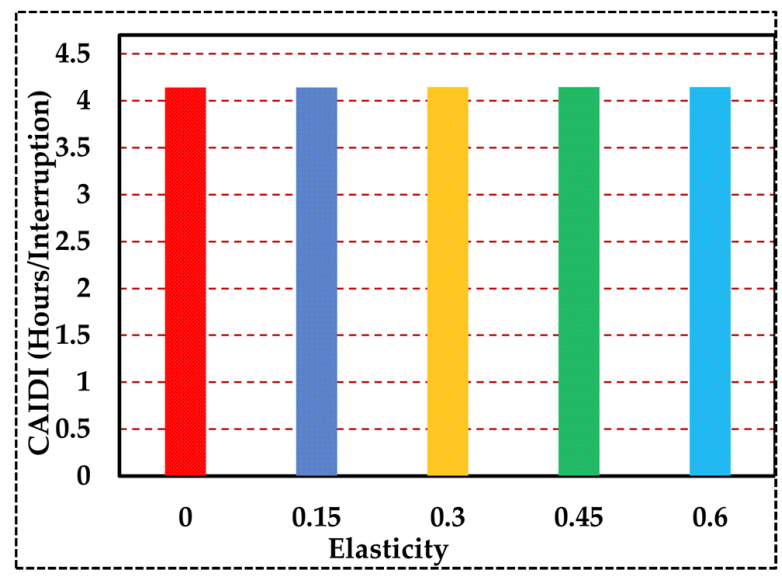

(c)

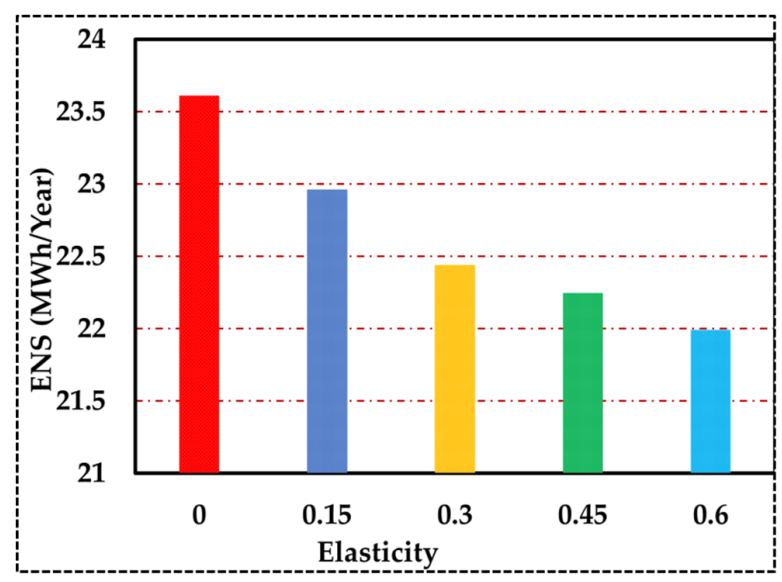

(e)

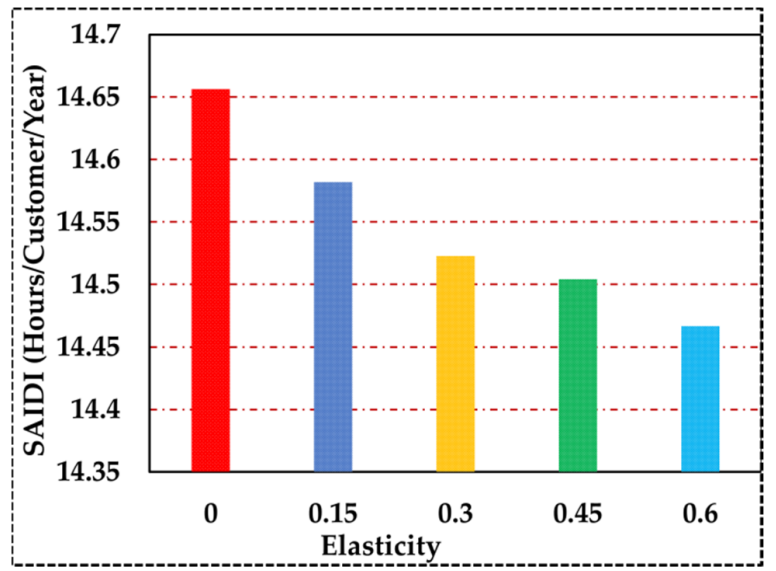

(b)

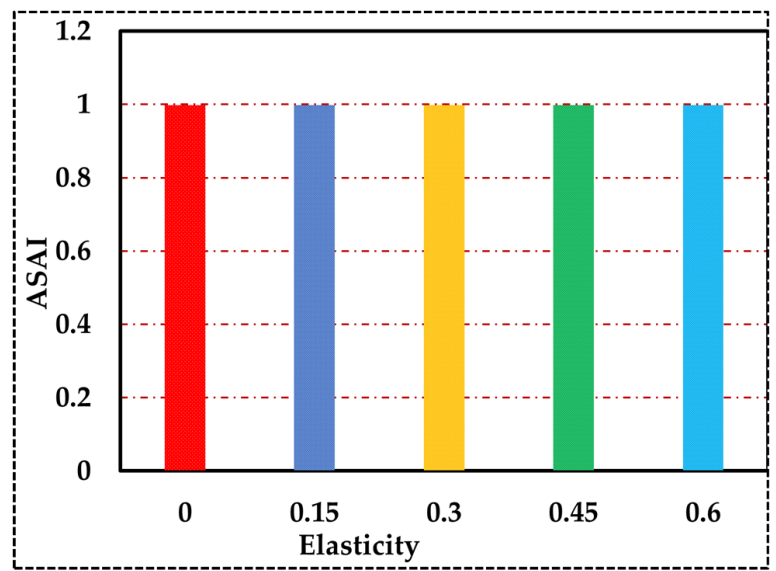

(d)

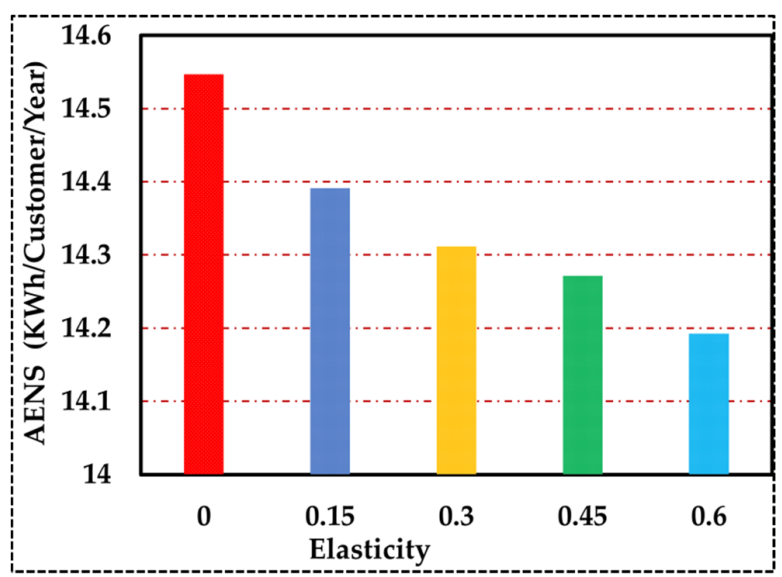

(f)

Figure 12. Changes in reliability indices based on elasticity for DR = 0.5. (a) SAIFI; (b) SAIDI; (c) CAIDI; (d) ASAI; (e) ENS; (f) AENS.

Figure 13 depicts the load curve for elasticity values of 3, 4, and 5, which are significant and uncommon values for elasticity. As can be seen, the load curve was affected by valleys and peaks, and as a result, the enhancement of reliability indices decreased. 


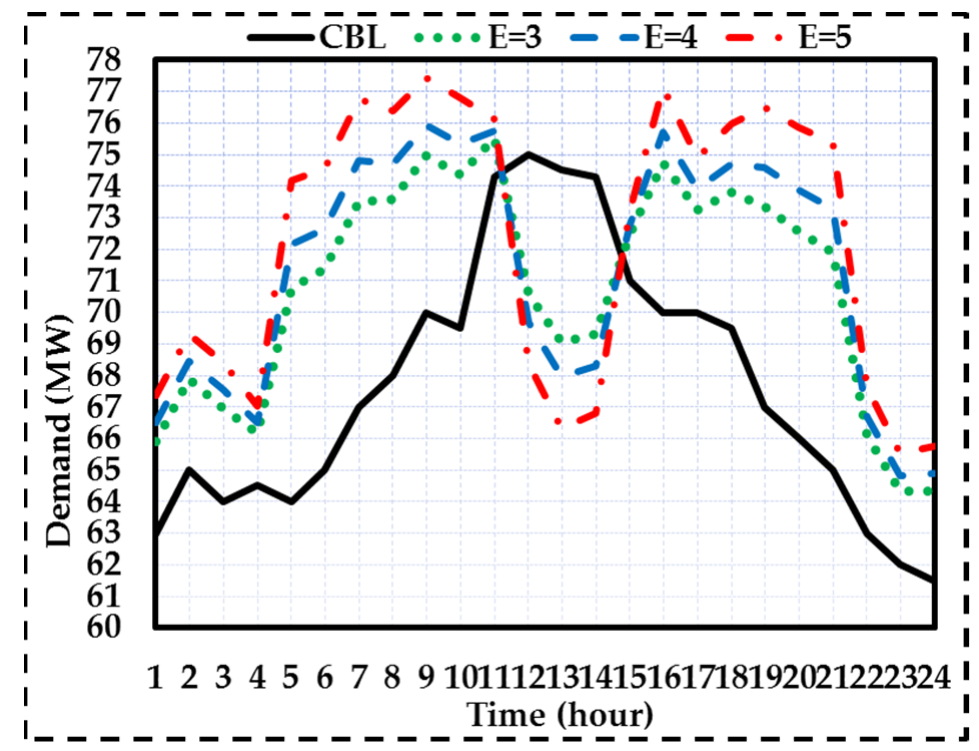

Figure 13. Changes in the consumption demand curve with respect to significant changes in elasticity.

\subsection{Sensitivity Analysis of Energy Not Supplied}

In this section, a sensitivity analysis was performed on the ENS of the load points based on DR changes and elasticity changes. As can be seen in Figure 14 and Table 14, as the elasticity and DR increased, the ENS of the load points decreased until the customers' responsiveness exceeded a threshold. As the customers' responsiveness further increased, the load peak was converted to a valley, and the increase in consumption generated peaks at the nonpeak points, increasing interruption probability at the nonpeak points.

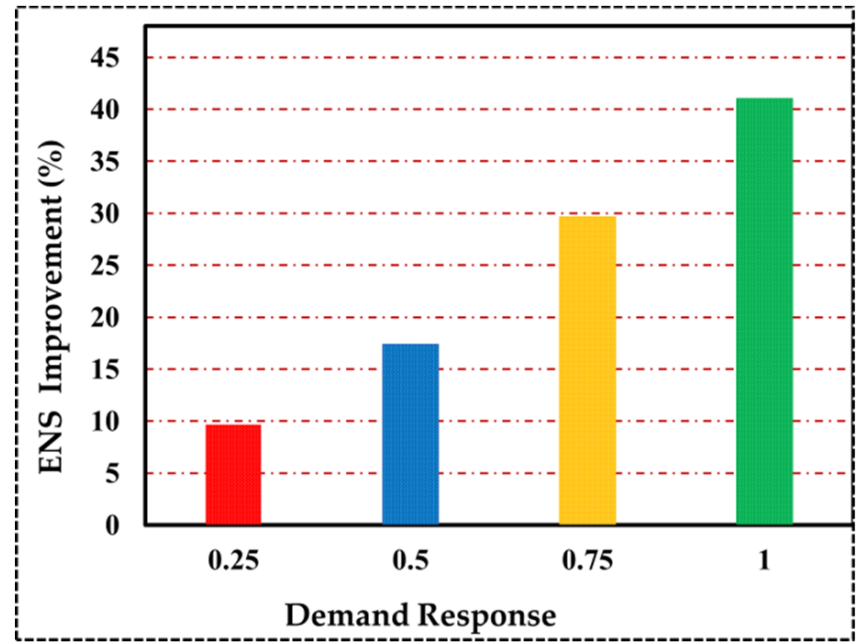

(a)

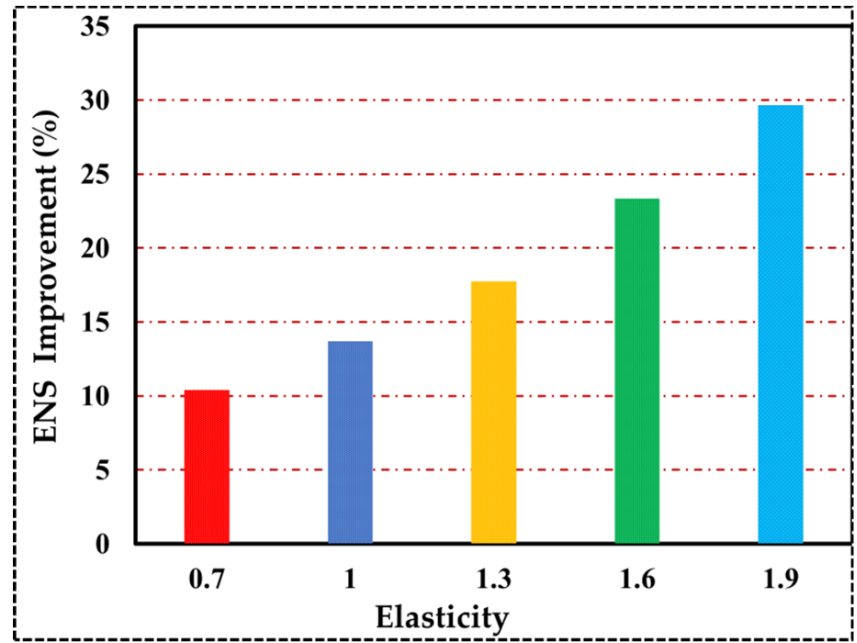

(b)

Figure 14. Improvement of ENS based on changes in demand response and elasticity. (a) Elasticity = 1.9; $(\mathbf{b}) \mathrm{DR}=0.75$.

Table 14. Changes in ENS based on simultaneous changes in DR and elasticity.

\begin{tabular}{ccccc}
\hline Self-Elasticity & DR $=\mathbf{0 . 2 5}$ & DR $=\mathbf{0 . 5 0}$ & DR $=\mathbf{0 . 7 5}$ & DR $=\mathbf{1}$ \\
\hline 0.7 & 22.6175 & 21.7581 & 21.1515 & 20.5449 \\
1 & 22.3521 & 21.2382 & 20.3716 & 19.1548 \\
1.3 & 21.8447 & 20.7182 & 19.4172 & 17.5737 \\
1.6 & 21.5848 & 20.1983 & 18.0944 & 15.3805 \\
1.9 & 21.3248 & 19.5021 & 16.6074 & 13.9134 \\
\hline
\end{tabular}




\subsection{Sensitivity Analysis of SAIFI}

In this section, a high elasticity was considered for sensitivity analysis to demonstrate the changes of the load profile. The sensitivity analysis of the SAIFI index showed that as the customers' sensitivity to energy price changed, the number of interruptions of the load points decreased because the consumption peak was shifted from heavy-load to low-load times (as shown in Figure 15 and Table 15). In fact, the customers tended to change their consumption to the times with energy price discounts. Therefore, at peak time, load peak and pressure on the lines and devices of the distribution system decreased and the number of interruptions decreased. In this analysis, it was shown that increasing customers' participation in the pricing tariff decreased SAIFI significantly until the load profile became smooth; after several load profile changes, at consumption peaks, the number of interruptions increased.

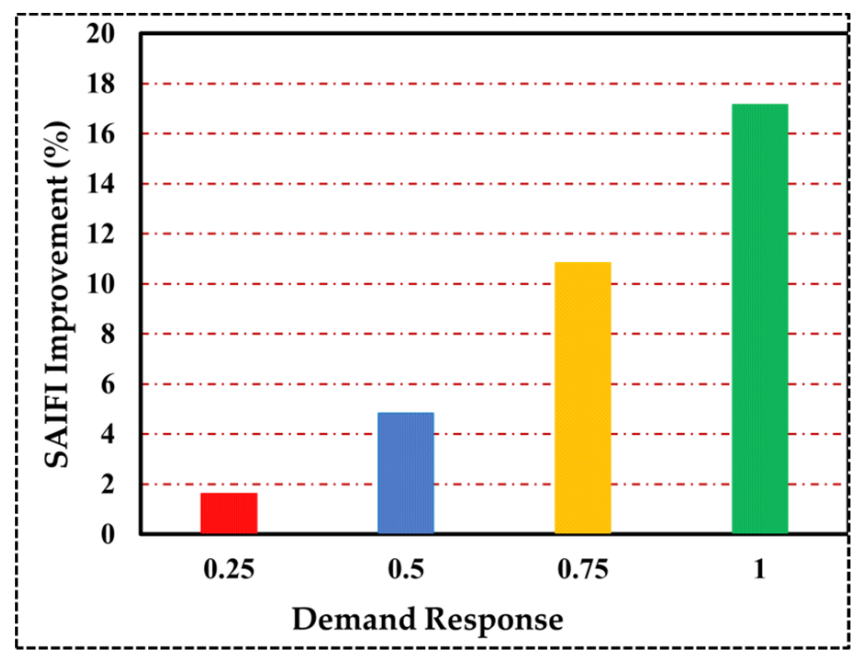

(a)

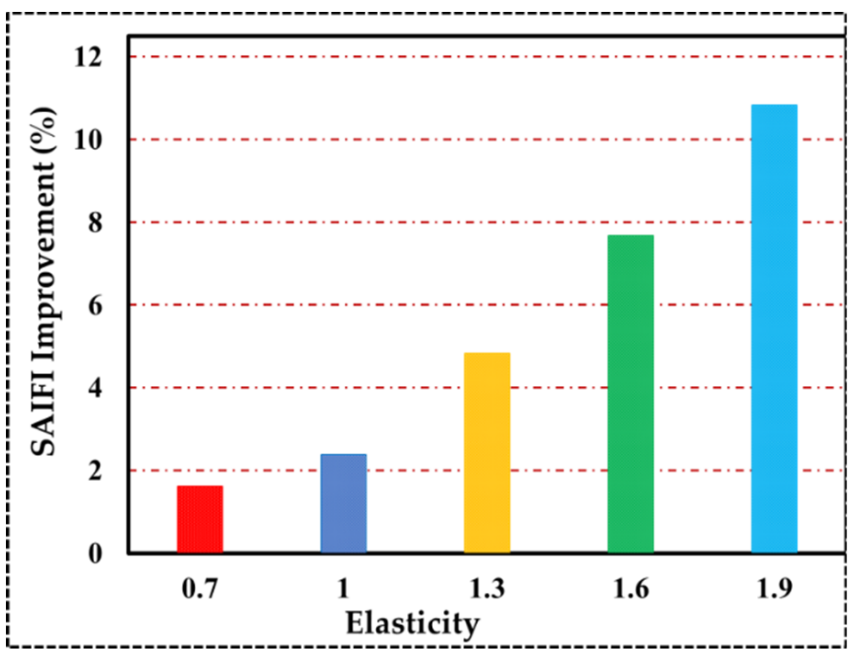

(b)

Figure 15. Improvement of the SAIFI index based on changes in demand response and elasticity. (a) Elasticity = 1.9; (b) $\mathrm{DR}=0.75$.

Table 15. Changes in the SAIFI index based on simultaneous changes in DR and elasticity.

\begin{tabular}{ccccc}
\hline Self-Elasticity & DR $=\mathbf{0 . 2 5}$ & DR $=\mathbf{0 . 5 0}$ & DR $=\mathbf{0 . 7 5}$ & DR $=\mathbf{1}$ \\
\hline 0.7 & 3.5038 & 3.4830 & 3.4829 & 3.4740 \\
1 & 3.5038 & 3.4830 & 3.4561 & 3.3494 \\
1.3 & 3.4829 & 3.4785 & 3.3693 & 3.2340 \\
1.6 & 3.4829 & 3.4336 & 3.2685 & 3.0606 \\
1.9 & 3.4829 & 3.3693 & 3.1566 & 2.9329 \\
\hline
\end{tabular}

\section{Conclusions}

In this study, an instantaneous pricing scheme is proposed for optimal operation and improved reliability of distribution systems. The numerical studies showed that employing the proposed tariff reduced the load peak and made the load profile more uniform by motivating customers to buy optimally. Thus, the operation costs and customers' invoices are decreased, and the final profit of the DSO is increased. On the other hand, since the load peak was decreased, more load could be connected to the side feeder when a fault occurs. Thus, the reliability of distribution system was improved. The results showed that as the customers' participation in the proposed tariff increased, the cost of buying energy from the market and the cost of interruptible loads decreased, because the energy consumption is shifted to low-load times, and the need to make interruptible contracts to cover emergency conditions decreased. Increasing DR and elasticity improved the reliability indices of the distribution system; the DR increased until the customers' responsiveness did not exceed a 
threshold, because further increase in the customers' responsiveness converted the load peak into a valley and generated peaks at nonpeak times by increasing consumption.

The proposed framework is capable of optimal emergency operation and restoration in different distribution systems with smart automation levels such as the IEEE119 bus and IEEE69 bus distribution systems. Since load restoration time played an essential role in designing the proposed model, said model necessitates using distribution networks with advanced metering infrastructure (AMI) and internet of things (IOT) that can detect and resolve faults in minimum time. Also, using DR programs on the consumer side necessitates using advanced communication networks with high reliability. Creating such smart structures in distribution networks for processing information on consumers and bidirectional communication systems based on IOT changes the operation costs. Thus, one practical constraint of this scheme is to convert conventional distribution systems to smart structures. Thus, in future studies, the main focus will be on developing a load restoration and operation model in microgrids that considers the uncertainty of DGs and DR programs associated with IOT.

Author Contributions: Conceptualization, M.R.M., M.S. and B.B.F.; methodology, M.R.M. and M.S.; software, M.R.M.; validation, M.R.M. and M.S.; formal analysis, M.R.M., M.S. and B.B.F.; investigation, M.S. and B.B.F.; resources, M.R.M. and B.B.F.; data curation, M.R.M.; writing-original draft preparation, M.R.M., M.S. and B.B.F.; writing-review and editing, M.R.M., M.S. and B.B.F.; visualization, M.R.M. and M.S.; supervision, M.S. and B.B.F.; project administration, M.S. and B.B.F.; funding acquisition, M.R.M. All authors have read and agreed to the published version of the manuscript.

Funding: This research received no external funding.

Institutional Review Board Statement: Not applicable.

Informed Consent Statement: Not applicable.

Data Availability Statement: The data presented in this study are available on request from the corresponding author.

Conflicts of Interest: The authors declare no conflict of interest.

\section{Nomenclature}

\begin{tabular}{|c|c|}
\hline \multicolumn{2}{|l|}{ A. Indices and Sets } \\
\hline$t, 1$ & Indices and set of time intervals, running from 1 to $\mathrm{T}$ \\
\hline $\mathrm{i}, \mathrm{k}, \mathrm{r}$ & Indices and set of network buses, running from 1 to 33 \\
\hline$g, N_{D G}$ & Index and number of distributed generation, running from 1 to 4 \\
\hline $\mathrm{T}$ & Index of total time ( $24 \mathrm{~h}$ a day) \\
\hline $\mathrm{N}$ & Set of linear model segments, running from 1 to 10 \\
\hline $\mathrm{J}$ & Set of different customers from 1 to 3 \\
\hline \multicolumn{2}{|c|}{ B. Parameters and Variables } \\
\hline$q_{t}$ & $\begin{array}{l}\text { Binary indicator denoting of the consumption peak hour, equal to } \\
1 \text { on peak, otherwise } 0\end{array}$ \\
\hline $\operatorname{Pr}_{t}^{\mathrm{BS}}, \operatorname{Pr}_{t}^{\mathrm{ch}}, \operatorname{Pr}_{\mathrm{t}}^{\mathrm{cr}}, \operatorname{Pr}_{\mathrm{t}}^{\mathrm{M}}, \operatorname{Pr}_{\mathrm{t}}^{\mathrm{IL}}$ & $\begin{array}{l}\text { Baseline rate, charge rate, credit rate, marginal price, and } \\
\text { interruptible load price (USD/MWh) }\end{array}$ \\
\hline $\mathrm{MUP}_{\mathrm{g}}, \mathrm{MDN}_{\mathrm{g}}$ & Minimum up and down time of DG unit (h) \\
\hline $\mathrm{P}_{\mathrm{g}}^{\mathrm{DGMax}}, \mathrm{P}_{\mathrm{g}}^{\mathrm{DGmin}}$ & $\begin{array}{l}\text { Maximum and minimum of DG capacity limit for } \\
\text { activepower }(\mathrm{KW})\end{array}$ \\
\hline $\mathrm{P}_{\mathrm{n}, \mathrm{g}}^{\mathrm{DGSegMax}}$ & Maximum capacity of DG generation segment (KW) \\
\hline $\mathrm{Z}_{\mathrm{g}}$ & DG startup cost parameter (USD) \\
\hline$I_{t, g}$ & $\begin{array}{l}\text { Binary variable denoting commitment status of DG unit } g \text { at time } \\
t \text {, equal to } 1 \text { if unit } g \text { is scheduled to be committed, otherwise } 0\end{array}$ \\
\hline
\end{tabular}




\begin{tabular}{|c|c|}
\hline $\mathrm{R}_{\mathrm{g}}^{\mathrm{UP}}, \mathrm{R}_{\mathrm{g}}^{\mathrm{Dn}}$ & Ramping-up and ramping- down rates ofDG unit $\mathrm{g}(\mathrm{KW})$ \\
\hline$r_{n, g}$ & Linear generation cost model parameter ofDG unit (USD/KWh) \\
\hline $\mathrm{C}_{\mathrm{g}}^{\mathrm{M}}$ & Minimum generation cost of unit g (USD/KWh) \\
\hline$\varepsilon, \mathrm{E}, \zeta$ & $\begin{array}{l}\text { Price elasticity coefficient, matrix of price elasticity factors, } \\
\text { customers' enrollment level on DR program }\end{array}$ \\
\hline$P D_{j}^{\text {int }}$ & $\begin{array}{l}\text { Demand of customer } \mathrm{j} \text { at time } \mathrm{t} \text { before implementing } \mathrm{DR} \\
\text { program (MW) }\end{array}$ \\
\hline $\operatorname{Pr}_{j}^{\text {int }}$ & $\begin{array}{l}\text { Initial value of electricity price offered tocustomer } j \text { at time } \\
t \text { (USD) }\end{array}$ \\
\hline$C_{t}^{\mathrm{ET}}$ & Cost of using smart measurement infrastructure (USD) \\
\hline $\mathrm{P}^{\text {Grid,Max }}$ & Maximum real power procured from outside grid (MW) \\
\hline $\mathrm{V}, \overline{\mathrm{V}}$ & Upper and lower allowed voltage magnitudes (pu) \\
\hline$e_{k, r, t, m}, d_{k, r, t, m}$ & Linearization constants (radian) \\
\hline $\mathrm{W}_{\mathrm{k}, \mathrm{r}, \mathrm{t}}$ & Linear approximation of $\cos \left(\delta_{\mathrm{k}, \mathrm{t}}-\delta_{\mathrm{r}, \mathrm{t}}\right)($ radian$)$ \\
\hline $\mathrm{G}_{\mathrm{k}, \mathrm{r}}\left(\mathrm{B}_{\mathrm{k}, \mathrm{r}}\right)$ & Line conductance and susceptance (from bus k to r) (ohm) \\
\hline $\mathrm{V}_{\mathrm{k}, \mathrm{t}}\left(\delta_{\mathrm{k}, \mathrm{t}}\right)$ & Voltage magnitude (voltage angle) at node $\mathrm{k}$ at time $\mathrm{t}(\mathrm{pu})$ \\
\hline $\mathrm{A}, \mathrm{B}, \mathrm{C}$ & Constant parameters for distribution function probability \\
\hline $\mathrm{L}_{\mathrm{a}}(\mathrm{i})$ & Average load of the ith load point (MW) \\
\hline$\lambda_{\mathrm{i}}, \mathrm{U}_{\mathrm{i}}, \mathrm{r}_{\mathrm{i}}$ & $\begin{array}{l}\text { Failure rate, average repair time, average annual disconnection } \\
\text { time }(\mathrm{h})\end{array}$ \\
\hline $\mathrm{N}_{\mathrm{i}}$ & Number of customers of the ith load point, running from 1 to 34 \\
\hline $\mathrm{LF}_{\mathrm{k}, \mathrm{r}, \mathrm{t}}^{\mathrm{P}}\left(\mathrm{LF}_{\mathrm{k}, \mathrm{r}, \mathrm{t}}^{\mathrm{Q}}\right)$ & Active (reactive) power flow from node $\mathrm{k}$ to $\mathrm{r}(\mathrm{MW})$ \\
\hline $\mathrm{BL}_{\mathrm{t}}^{\text {Total }}$ & Total bill received from all customers at time $t$ (USD) \\
\hline$C_{t}^{\text {Total }}$ & Cost of supplying the DS energy at a specific hour (USD) \\
\hline $\operatorname{PD}_{\mathrm{DR}}\left(\mathrm{PD}_{\mathrm{NDR}}\right)$ & $\begin{array}{l}\text { Power consumption of customers that participate (do not } \\
\text { participate) in the proposed scheme (MW) }\end{array}$ \\
\hline $\mathrm{PD}_{\mathrm{t}}^{\mathrm{RT}}\left(\mathrm{QD}_{\mathrm{t}}^{\mathrm{RT}}\right)$ & $\begin{array}{l}\text { Active (reactive) power consumed by customers in period. } \\
\text { MW (MVAR) }\end{array}$ \\
\hline$P_{t, g}^{D G}\left(Q_{t, g}^{D G}\right)$ & Active (reactive) power generated by each DG unit. KW (KVAR) \\
\hline$P_{t}^{I L . C}\left(Q_{t}^{I L . C}\right)$ & Active (reactive) power of interruptible load. MW (MVAR) \\
\hline$P_{t}^{\text {Grid }}\left(Q_{t}^{\text {Grid }}\right)$ & Active (reactive) power purchased from grid. MW (MVAR) \\
\hline$\triangle \mathrm{PD}$ & Matrix of changes in demand (MW) \\
\hline$\Delta \operatorname{Pr}$ & Price change vector (USD) \\
\hline PDaily & The DSO profit from daily operation (USD) \\
\hline $\mathrm{C}_{\mathrm{t}, \mathrm{g}}^{\mathrm{DG}}$ & Piecewise linear cost function of energy generation by DGs (USD) \\
\hline$P_{t, n, g}$ & $\begin{array}{l}\text { Power generation for DG } \mathrm{g} \text { for segment } \mathrm{n} \text { of piecewise linear } \\
\text { cost function. }(\mathrm{KW})\end{array}$ \\
\hline $\mathrm{C}_{\mathrm{t}, \mathrm{g}}^{\mathrm{SU}}$ & Startup cost of DG unit g (USD) \\
\hline RT, ST & Repair time, switching time $(\mathrm{h})$ \\
\hline $\mathrm{D}_{\mathrm{i}}$ & New demand for each bus (MW) \\
\hline \multicolumn{2}{|c|}{ C. Abbreviations } \\
\hline SAIFI & System average interruption frequency index \\
\hline SAIDI & System average interruption duration index \\
\hline CAIDI & Customer average interruption duration index \\
\hline ASAI & Average service availability index \\
\hline ASUI & Average service unavailability index \\
\hline AENS & Average energy not supplied \\
\hline ENS & Energy not supplied \\
\hline EENS & Expected energy not supplied \\
\hline
\end{tabular}




\begin{tabular}{ll}
\hline CBL & Customer baseline load (MW) \\
CBL $_{C}$ & Demand from customers that participate in the DR program (MW) \\
DG & Distributed generation \\
DR & Demand response \\
PSO & Particle swarm optimization \\
DS & Distribution system \\
MCS & Monte Carlo simulation \\
Bus $_{\text {state }}$ & Bus state \\
Load $_{\text {state }}$ & Load state \\
Bus Order & Bus order \\
MILP & Mixed integer linear programming model \\
RTP & Real-time pricing \\
MG & Microgrid \\
DSO & Distribution system operator \\
IL & Interruptible load \\
DRA & Demand response aggregators \\
RTM & Real-time market \\
CCP & Critical peak pricing \\
TOU & Time of use \\
RTP & Real time pricing \\
AMI & Advanced metering infrastructure \\
IOT & Internet of things \\
\hline
\end{tabular}

\section{References}

1. Gholami, A.; Shekari, T.; Grijalva, S. Proactive management of microgrids for resiliency enhancement: An adaptive robust approach. IEEE Trans. Sustain. Energy 2017, 10, 470-480. [CrossRef]

2. Rashidizadeh-Kermani, H.; Vahedipour-Dahraie, M.; Shafie-Khah, M.; Catalao, J.P. A bi-level risk-constrained offering strategy of a wind power producer considering demand side resources. Int. J. Electr. Power Energy Syst. 2019, 104, 562-574. [CrossRef]

3. Algarni, A.S.; Bhattacharya, K. A Generic Operations Framework for Discos in Retail Electricity Markets. IEEE Trans. Power Syst. 2009, 24, 356-367. [CrossRef]

4. Jesus, P.D.; De Leão, M.P.; Yusta, J.M.; Khodr, H.M.; Urdaneta, A.J. Uniform marginal pricing for the remuneration of distribution networks. IEEE Trans. Power Syst. 2005, 20, 1302-1310.

5. Safdarian, A.; Fotuhi-Firuzabad, M.; Lehtonen, M. Integration of price-based demand response in DisCos' short-term decision model. IEEE Trans. Smart Grid 2014, 5, 2235-2245. [CrossRef]

6. Parvania, M.; Fotuhi-Firuzabad, M. Integrating load reduction into wholesale energy market with application to wind power integration. IEEE Syst. J. 2011, 6, 35-45. [CrossRef]

7. Sioshansi, R. Evaluating the impacts of real-time pricing on the cost and value of wind generation. IEEE Trans. Power Syst. 2009, 25, 741-748. [CrossRef]

8. Chiu, W.Y.; Sun, H.; Poor, H.V. Energy imbalance management using a robust pricing scheme. IEEE Trans. Smart Grid 2012, 4, 896-904. [CrossRef]

9. Pillay, A.; Karthikeyan, S.P.; Kothari, D.P. Congestion management in power systems-A review. Int. J. Electr. Power Energy Syst. 2015, 70, 83-90. [CrossRef]

10. Abapour, S.; Nojavan, S.; Abapour, M. Multi-objective short-term scheduling of active distribution networks for benefit maximization of DisCos and DG owners considering demand response programs and energy storage system. J. Mod. Power Syst. Clean Energy 2018, 6, 95-106. [CrossRef]

11. Narain, A.; Srivastava, S.K.; Singh, S.N. Congestion management approaches in restructured power system: Key issues and challenges. Electr. J. 2020, 33, 106715. [CrossRef]

12. Safdar, M.; Hussain, G.A.; Lehtonen, M. Costs of demand response from residential customers' perspective. Energies 2019, 12, 1617. [CrossRef]

13. Zhou, S.; Zou, F.; Wu, Z.; Gu, W.; Hong, Q.; Booth, C. A smart community energy management scheme considering user dominated demand side response and P2P trading. Int. J. Electr. Power Energy Syst. 2020, 114, 105378. [CrossRef]

14. Henríquez, R.; Wenzel, G.; Olivares, D.E.; Negrete-Pincetic, M. Participation of demand response aggregators in electricity markets: Optimal portfolio management. IEEE Trans. Smart Grid 2017, 9, 4861-4871. [CrossRef]

15. Imani, M.H.; Niknejad, P.; Barzegaran, M.R. The impact of customers' participation level and various incentive values on implementing emergency demand response program in microgrid operation. Int. J. Electr. Power Energy Syst. 2018, 96, 114-125. [CrossRef]

16. Chen, B.; Ye, Z.; Chen, C.; Wang, J. Toward a MILP modeling framework for distribution system restoration. IEEE Trans. Power Syst. 2018, 34, 1749-1760. [CrossRef] 
17. Haghifam, S.; Dadashi, M.; Zare, K.; Seyedi, H. Optimal operation of smart distribution networks in the presence of demand response aggregators and microgrid owners: A multi follower Bi-Level approach. Sustain. Cities Soc. 2020, 55, 102033. [CrossRef]

18. Ghasemi, H.; Aghaei, J.; Gharehpetian, G.B.; Safdarian, A. MILP model for integrated expansion planning of multi-carrier active energy systems. IET Gener. Transm. Distrib. 2019, 13, 1177-1189. [CrossRef]

19. Moghimi, F.H.; Barforoushi, T. A short-term decision-making model for a price-maker distribution company in wholesale and retail electricity markets considering demand response and real-time pricing. Int. J. Electr. Power Energy Syst. 2020, 117, 105701. [CrossRef]

20. Khalkhali, H.; Hosseinian, S.H. Novel residential energy demand management framework based on clustering approach in energy and performance-based regulation service markets. Sustain. Cities Soc. 2019, 45, 628-639. [CrossRef]

21. Damisa, U.; Nwulu, N.I.; Sun, Y. Microgrid energy and reserve management incorporating prosumer behind-the-meter resources. IET Renew. Power Gener. 2018, 12, 910-919. [CrossRef]

22. Vahedipour-Dahraei, M.; Najafi, H.R.; Anvari-Moghaddam, A.; Guerrero, J.M. Security-constrained unit commitment in AC microgrids considering stochastic price-based demand response and renewable generation. Int. Trans. Electr. Energy Syst. 2018 28, e2596. [CrossRef]

23. Vahedipour-Dahraie, M.; Najafi, H.R.; Anvari-Moghaddam, A.; Guerrero, J.M. Study of the effect of time-based rate demand response programs on stochastic day-ahead energy and reserve scheduling in islanded residential microgrids. Appl. Sci. 2017, 7, 378. [CrossRef]

24. Vahedipour-Dahraie, M.; Rashidizadeh-Kermani, H.; Najafi, H.R.; Anvari-Moghaddam, A.; Guerrero, J.M. Stochastic security and risk-constrained scheduling for an autonomous microgrid with demand response and renewable energy resources. IET Renew. Power Gener. 2017, 11, 1812-1821. [CrossRef]

25. Safdarian, A.; Fotuhi-Firuzabad, M.; Lehtonen, M. Benefits of demand response on operation of distribution networks: A case study. IEEE Syst. J. 2014, 10, 189-197. [CrossRef]

26. Safdarian, A.; Fotuhi-Firuzabad, M.; Lehtonen, M. Demand response from residential consumers: Potentials, barriers, and solutions. In Smart Grids and Their Communication Systems; Springer: Singapore, 2019; pp. 255-279.

27. Lee, J.; Yoo, S.; Kim, J.; Song, D.; Jeong, H. Improvements to the customer baseline load (CBL) using standard energy consumption considering energy efficiency and demand response. Energy 2018, 144, 1052-1063. [CrossRef]

28. Xu, Z.; Gao, Y.; Hussain, M.; Cheng, P. Demand side management for smart grid based on smart home appliances with renewable energy sources and an energy storage system. Math. Probl. Eng. 2020, 2020, 9545439. [CrossRef]

29. Narimani, M.R. Demand Side Management for Homes in Smart Grids. In Proceedings of the 2019 North American Power Symposium (NAPS), Wichita, KS, USA, 13-15 October 2019; pp. 1-6.

30. Feng, J.; Zeng, B.; Zhao, D.; Wu, G.; Liu, Z.; Zhang, J. Evaluating demand response impacts on capacity credit of renewable distributed generation in smart distribution systems. IEEE Access 2017, 6, 14307-14317. [CrossRef]

31. Popović, Ž.; Knezević, S.; Brbaklić, B. Optimal reliability improvement strategy in radial distribution networks with island operation of distributed generation. IET Gener. Transm. Distrib. 2018, 12, 78-87. [CrossRef]

32. Farzin, H.; Fotuhi-Firuzabad, M.; Moeini-Aghtaie, M. Role of outage management strategy in reliability performance of multimicrogrid distribution systems. IEEE Trans. Power Syst. 2017, 33, 2359-2369. [CrossRef]

33. Hashemi-Dezaki, H.; Agah, S.M.M.; Askarian-Abyaneh, H.; Haeri-Khiavi, H. Sensitivity analysis of smart grids reliability due to indirect cyber-power interdependencies under various DG technologies, DG penetrations, and operation times. Energy Convers. Manag. 2016, 108, 377-391. [CrossRef]

34. Hashemi-Dezaki, H.; Askarian-Abyaneh, H.; Haeri-Khiavi, H. Impacts of direct cyber-power interdependencies on smart grid reliability under various penetration levels of microturbine/wind/solar distributed generations. IET Gener. Transm. Distrib. 2016, 10, 928-937. [CrossRef]

35. Escalera, A.; Hayes, B.; Prodanovic, M. Analytical method to assess the impact of distributed generation and energy storage on reliability of supply. CIRED-Open Access Proc. J. 2017, 2017, 2092-2096. [CrossRef]

36. Du, S.; Zio, E.; Kang, R. A new analytical approach for interval availability analysis of Markov repairable systems. IEEE Trans. Reliab. 2017, 67, 118-128. [CrossRef]

37. Wang, X.; Karki, R. Exploiting PHEV to augment power system reliability. IEEE Trans. Smart Grid 2016, 8, 2100-2108. [CrossRef]

38. Hashemi-Dezaki, H.; Hamzeh, M.; Askarian-Abyaneh, H.; Haeri-Khiavi, H. Risk management of smart grids based on managed charging of PHEVs and vehicle-to-grid strategy using Monte Carlo simulation. Energy Convers. Manag. 2015, 100, 262-276. [CrossRef]

39. Fünfgeld, S.; Holzäpfel, M.; Frey, M.; Gauterin, F. Stochastic forecasting of vehicle dynamics using sequential monte carlo simulation. IEEE Trans. Intell. Veh. 2017, 2, 111-122. [CrossRef]

40. Shojaabadi, S.; Abapour, S.; Abapour, M.; Nahavandi, A. Simultaneous planning of plug-in hybrid electric vehicle charging stations and wind power generation in distribution networks considering uncertainties. Renew. Energy 2016, 99, 237-252. [CrossRef]

41. Moeini-Aghtaie, M.; Farzin, H.; Fotuhi-Firuzabad, M.; Amrollahi, R. Generalized analytical approach to assess reliability of renewable-based energy hubs. IEEE Trans. Power Syst. 2016, 32, 368-377. [CrossRef]

42. Chen, C.; Wu, W.; Zhang, B.; Singh, C. An analytical adequacy evaluation method for distribution networks considering protection strategies and distributed generators. IEEE Trans. Power Deliv. 2014, 30, 1392-1400. [CrossRef] 
43. Marzband, M.; Azarinejadian, F.; Savaghebi, M.; Guerrero, J.M. An optimal energy management system for islanded microgrids based on multiperiod artificial bee colony combined with Markov chain. IEEE Syst. J. 2015, 11, 1712-1722. [CrossRef]

44. Aghdam, F.H.; Abapour, M. Reliability and cost analysis of multistage boost converters connected to PV panels. IEEE J. Photovolt. 2016, 6, 981-989. [CrossRef]

45. Dong, J.; Gao, F.; Guan, X.; Zhai, Q.; Wu, J. Storage-reserve sizing with qualified reliability for connected high renewable penetration micro-grid. IEEE Trans. Sustain. Energy 2016, 7, 732-743. [CrossRef]

46. Sun, S.; Yang, Q.; Yan, W. A novel Markov-based temporal-SoC analysis for characterizing PEV charging demand. IEEE Trans. Ind. Inform. 2017, 14, 156-166. [CrossRef]

47. Iversen, E.B.; Møller, J.K.; Morales, J.M.; Madsen, H. Inhomogeneous Markov models for describing driving patterns. IEEE Trans. Smart Grid 2016, 8, 581-588. [CrossRef]

48. Farzin, H.; Fotuhi-Firuzabad, M.; Moeini-Aghtaie, M. Reliability studies of modern distribution systems integrated with renewable generation and parking lots. IEEE Trans. Sustain. Energy 2016, 8, 431-440. [CrossRef]

49. Reigosa, P.D.; Wang, H.; Yang, Y.; Blaabjerg, F. Prediction of bond wire fatigue of IGBTs in a PV inverter under a long-term operation. IEEE Trans. Power Electron. 2015, 31,7171-7182.

50. Sekhavatmanesh, H.; Cherkaoui, R. Analytical approach for active distribution network restoration including optimal voltage regulation. IEEE Trans. Power Syst. 2018, 34, 1716-1728. [CrossRef]

51. Zhu, J.; Yuan, Y.; Wang, W. An exact microgrid formation model for load restoration in resilient distribution system. Int. J. Electr. Power Energy Syst. 2020, 116, 105568. [CrossRef]

52. Gilani, M.A.; Kazemi, A.; Ghasemi, M. Distribution system resilience enhancement by microgrid formation considering distributed energy resources. Energy 2020, 191, 116442. [CrossRef]

53. Nozhati, S.; Sarkale, Y.; Chong, E.K.; Ellingwood, B.R. Optimal stochastic dynamic scheduling for managing community recovery from natural hazards. Reliab. Eng. Syst. Saf. 2020, 193, 106627. [CrossRef]

54. Choopani, K.; Hedayati, M.; Effatnejad, R. Self-healing optimization in active distribution network to improve reliability, and reduction losses, switching cost and load shedding. Int. Trans. Electr. Energy Syst. 2020, 30, e12348. [CrossRef]

55. Sinishaw, G.Y.; Bantyirga, B.; Abebe, K. Analysis of smart grid technology application for power distribution system reliability enhancement: A case study on Bahir Dar power distribution. Sci. Afr. 2021, 21, e00840. [CrossRef]

56. López-Prado, J.L.; Vélez, J.I.; Garcia-Llinás, G.A. Reliability Evaluation in Distribution Networks with Microgrids: Review and Classification of the Literature. Energies 2020, 13, 6189. [CrossRef]

57. Vai, V.; Suk, S.; Lorm, R.; Chhlonh, C.; Eng, S.; Bun, L. Optimal Reconfiguration in Distribution Systems with Distributed Generations Based on Modified Sequential Switch Opening and Exchange. Appl. Sci. 2021, 11, 2146. [CrossRef]

58. The General Algebraic Modeling System (GAMS) Software. Available online: http://www.gams.com (accessed on 15 September 2021).

59. Aljohani, T.; Beshir, M. Distribution system reliability analysis for smart grid applications. Smart Grid Renew. Energy 2017, 8, 240-251. [CrossRef] 